\title{
EL LABERINTO MARROQUÍ, PIEDRA DE TROPIEZO DE \\ LIBERALES Y AUTORITARIOS (1912-1926)
}

\author{
Morocco's international crossroads, a stumbling block for liberals and \\ authoritarians (1912-1926)
}

Pablo La Porte

Heriot-Watt University

P.La_Porte@hw.ac.uk

Recibido: 20-04-2021 - Aceptado: 14-07-2021

Cómo citar este artículo/Citation:

Pablo La Porte, "El laberinto marroquí, piedra de tropiezo de liberales y autoritarios (1912-1926)", Hispania Nova, 20 (2022): 692 a 736.

DOI: https://doi.org/10.20318/hn.2022.6474
Copyright: (C) HISPANIA NOVA es una revista debidamente registrada, con ISSN 1138-7319 y Depósito Legal M 9472-1998. Los textos publicados están -si no se indica lo contrario- bajo una licencia Reconocimiento-Sin obras derivadas 3.0 España de Creative Commons. Puede copiarlos, distribuirlos y comunicarlos públicamente siempre que cite su autor y la revista y la institución que los publica y no haga con ellos obras derivadas. La licencia completa se puede consultar en: http://creativecommons.org/licenses/by-nd/3.0/es/deed.es
Resumen: Los intereses coloniales de España en Marruecos se vieron circunscritos por el equilibrio de fuerzas establecido por Inglaterra y Francia en el Mediterráneo Occidental. Las ambiciones españolas se vieron también obstaculizadas por la rivalidad con Francia, su vecino colonial en Marruecos, que determinó la problemática naturaleza del proyecto marroquí para España y su influencia adversa sobre la política peninsular.

Palabras clave: Protectorado español, Marruecos, colonialismo, guerra del Rif (1921-1926).

\begin{abstract}
Spanish colonial interests in Morocco were constrained by the international balance of power held by Britain and France in the Western Mediterranean. Spanish ambitions in Morocco were also hampered by local rivalries with her colonial neighbour, France, which determined the problematic nature of the Spanish colonial project and, ultimately, its enduring and negative effects on the Peninsula.
\end{abstract}

Keywords: Spanish Protectorate, Morocco, colonialism, Rif War (1921-1926 


\section{INTRODUCCIÓN}

La zona de influencia española en Marruecos fue el escenario de los acontecimientos que desencadenaron la crisis final del régimen de la Restauración en España (1875-1923). Asimismo, el problema marroquí se convirtió en el desafío más apremiante al que hubo de hacer frente la dictadura de Primo de Rivera (1923-1930) en sus primeros años. No es sorprendente, por tanto, que la atención de los historiadores se haya visto frecuentemente atraída por la colonización española y por sus repercusiones, tanto en la Península como en el Protectorado ${ }^{1}$. Ciertamente, como se ha señalado abundantemente en la historiografía, hay razones sobradas para atribuir la perennidad de la cuestión marroquí a la incoherencia y las contradicciones de la política colonial española, enredada en el faccionalismo mezquino y la paralela desintegración de los partidos dinásticos en las primeras décadas del siglo XX. Hay motivos también para achacarla a la ineficacia de las fuerzas armadas $y$, en particular, a las carencias del Ejército de África, atrapado entre la falta de recursos, la escasa preparación de sus tropas y la ineptitud de muchos de sus mandos. A ello podrían añadirse las coordenadas geográficas y las condiciones sociales de la zona española, caracterizadas por las dificultades del terreno y el carácter belicoso e indómito de las tribus que lo poblaban, particularmente en la región del Rif $^{2}$.

Este trabajo, sin embargo, adopta una perspectiva internacional para explicar los motivos que convirtieron la aventura marroquí (la desaventura, quizás) en el detonante final de la crisis de la Restauración y en el reto más acuciante de la naciente dictadura de Primo de Rivera. A esta aproximación contribuyen algunos factores de importancia que pueden resumirse brevemente. La instauración del Protectorado en Marruecos fue resultado más o menos directo de la pugna de intereses entre las potencias imperiales europeas, particularmente Inglaterra y Francia, y de su reparto de influencias en el Mediterráneo Occidental. El Tratado de Fez de marzo de 1912 y el posterior Convenio hispano-francés de noviembre del mismo año dividieron el Imperio del Sultán en tres

\footnotetext{
${ }^{1}$ Una tradición que continúa hoy en los trabajos de Akmir, Aziza, Jensen, López García, Marín, Martín Corrales, Pennell, Villanova o Wyrtzen, entre otros.

2 Éstos y otros motivos se analizan en las obras de Balfour, Boyd o Payne, a las que se hace referencia en las páginas siguientes.
} 
zonas bajo administraciones diversas - Tánger, el Protectorado francés y la Zona de influencia española - haciendo depender la buena marcha del proyecto, tan ambicioso como probablemente quimérico, de un consenso internacional y, particularmente, de la voluntad franco-española "de armonizar los intereses de los dos países en Marruecos"”. La sintonía entre las potencias colonizadoras, por tanto, se convirtió en uno de los pilares del régimen colonial en Marruecos, peculiarmente relevante en las etapas de dominación de un territorio en buena parte desconocido. Estas circunstancias resultaron evidentes cuando las armas españolas se aproximaron a las montañas del Rif y, más aún, cuando la resistencia rifeña ofreció un obstáculo infranqueable para las mismas. Dicho de otro modo, la prolongación crónica y la insolubilidad aparente del problema marroquí para España, sobre todo a partir del desastre de Annual (1921), se debió en mayor medida que a otros factores a la falta de entendimiento y cooperación con Francia, que convirtió la sumisión de las tribus del Rif en una misión poco menos que inalcanzable para el Ejército de África, enquistando una situación que resultó insostenible para el régimen de la Restauración y que presentó un formidable escollo a la dictadura de Primo de Rivera.

Esta perspectiva de estudio no pretende minusvalorar las habilidades estratégicas ni el espíritu combativo de las tribus del Rif bajo el liderazgo de Abd el Krim, ni ignorar tampoco las profundas deficiencias del ejército colonial español. Tratará de situar, sin embargo, la raíz del problema marroquí y su prolongamiento agónico en su dimensión internacional. En la consideración de estos factores, por otra parte, no ha primado el interés por ilustrar las desavenencias creadas por el problema marroquí entre las naciones "protectoras", un enfoque bastante frecuente en la literatura, sino más bien el deseo de verificar las consecuencias de las mismas en el desarrollo de la acción colonial $^{4}$.

\footnotetext{
3 “Convenio fijando la respectiva situación de España y Francia en Marruecos: firmado en Madrid el 27 de noviembre de 1912", Dipublico.org, 29 de enero de 2017, https://www.dipublico.org/108651/convenio-fijando-la-respectiva-situacion-de-espana-y-francia-enmarruecos-firmado-en-madrid-el-27-de-noviembre-de-1912/.

${ }^{4}$ La dimensión internacional de la colonización marroquí incluye una larga lista de autores, algunas de cuyas publicaciones se remontan a la instauración misma del Protectorado. Entre otros, puede mencionarse a Allain, Ayache, Benjelloun, Goicoechea, Harris, Julien, Kharchich, Koerner, Kunz, Larramendi, Morales Lezcano, Sasse, Wolf o Woolman, cuyas obras se incluyen en la bibliografía.
} 


\section{MARRUECOS EN LA MESA DE LOS GRANDES (1880-1912)}

Un conjunto de circunstancias se alinearon para hacer del Sultanato marroquí una encrucijada de ambiciones internacionales a comienzos del siglo XX. En primer lugar, Marruecos había subsistido de manera singular como uno de los pocos territorios africanos que conservaban su independencia tras la conferencia de Berlín (1885), una posición relativamente insólita que compartía con el Imperio etíope y Liberia. Ciertamente, el Sultanato había sufrido un cerco diplomático europeo desde mediados del siglo XIX, alimentado por las pretensiones francesas desde Argelia y las deudas contraídas con Inglaterra (sobre todo tras la derrota de Isly contra Francia), que habían debilitado sus estructuras políticas y sociales y reforzado su dependencia económica. A ello se habían sumado incidentes fronterizos con España, que se convirtieron en operaciones militares de cierto alcance en la guerra de Tetuán en 1880 y en la campaña de Melilla en 1893. Sus más de ocho siglos de existencia, sin embargo, habían dotado al imperio marroquí de una entidad política, de una textura social y de unas tradiciones culturales desconocidas en otras partes del continente africano y simbolizadas en la figura del Sultán como líder político y religioso, aspectos estos que le permitieron navegar con cierto aplomo las aguas internacionales de finales del siglo XIX. Posiblemente a ello contribuyera el relativo desconocimiento del país, un lugar aún misterioso a pesar de su proximidad geográfica a Europa, y en el que aventureros, agentes comerciales y misioneros habían restringido sus movimientos a enclaves estables y protegidos, al amparo de las barreras naturales del territorio. A comienzos del siglo XX, sin embargo, cuando ya se había consumado el reparto de África, la independencia de Marruecos no podía por menos que reavivar una atención en la que concurrían no solo los intereses acreditados de las tradicionales potencias imperiales, sino también las aspiraciones de potencias menores con renovados designios en el Mediterráneo Occidental (Italia y España) ${ }^{5}$.

En segundo término, Marruecos se vio inexorable y progresivamente involucrado en las tensiones provocadas por la expansión de los diversos imperios coloniales, y más precisamente, en las consecuencias del encuentro inevitable entre el imperio vertical inglés y el imperio horizontal francés en África. La derrota francesa en

\footnotetext{
${ }^{5}$ Un recorrido reciente en Susan Miller, A History of Modern Morocco. (Cambridge: CUP, 2013), 28-87.
} 
Fashoda (1898) transformó prontamente el Sultanato en moneda de cambio para estabilizar las relaciones entre ambos países, en una transacción en la que a la libertad de acción de Inglaterra en Egipto, esencial para el mantenimiento de las comunicaciones con la India a través de Suez, respondió el predominio de Francia en Marruecos, llamado a completar el África Occidental francesa. El reparto de zonas de influencia derivado del "98 francés", por tanto, confirmó la reconocimiento de Marruecos como un área de predominante influencia francesa, bajo la mirada vigilante del Foreign Office británico ${ }^{6}$.

Finalmente, y como elemento desencadenante, Marruecos fue el territorio elegido por el emperador alemán Guillermo II para plantar cara a la Entente francobritánica, y para manifestar dicho reto de un modo provocador y belicista, enteramente alejado del tacto predominante en la anterior diplomacia bismarkiana. A dicho enfrentamiento contribuyó, irónicamente, la propia diplomacia marroquí, que desde mediados del siglo XIX había optado por una estrategia defensiva encaminada a agudizar las rivalidades entre las potencias europeas con el fin de preservar su supervivencia, y a la que Alemania (como antes los Estados Unidos o Inglaterra) había sido atraída y cortejada con ese propósito ${ }^{7}$. Las crisis marroquíes de 1905 y 1911, sin embargo, finalizaron con la pretensión aún acariciada en Fez de que Marruecos podría continuar su singular aislamiento en los márgenes de la expansión colonial y marcaron a partir de entonces su inextricable vinculación a los intereses y la deriva imperialista europea.

A esta confluencia de intereses acudiría España en una situación de desventaja y en unas condiciones de inferioridad evidentes. Por una parte, la mayoría de los gobernantes españoles de comienzos de siglo estaban de acuerdo en la necesidad ineludible de mantener y consolidar la presencia española al otro lado del Estrecho con el fin de evitar la presencia exclusiva de Francia a ambos lados del territorio nacional,

\footnotetext{
${ }^{6}$ John Perry, "A Shared Sea: The Axes of French and British Imperialism in the Mediterranean, 17981914". En James R. Fichter (ed.), British and French Colonialism in Africa, Asia and the Middle East (Cham: Palgrave Macmillan, 2019), 113-130.

7 Sigue siendo enormemente interesante la obra de Thérèse Benjelloun, Visages de la diplomatie marocaine depuis 1844. (Casablanca: Eddif, 1991), 107-111. Véase también John C. Rohl, Wilhelm II: Into the Abyss of War and Exile, 1900-1941. (Cambridge: CUP, 2017), 329-353.
} 
interpretada como una amenaza a la seguridad del país ${ }^{8}$. Por otra parte, eran igualmente conscientes de que las capacidades coloniales de España eran muy limitadas y podían verse fácilmente sobrepasadas en Marruecos. De estas contradicciones nació una actitud prudente, vacilante y ambigua, que acabaría caracterizando la política colonial española.

En realidad, para España, la presencia en Marruecos constituía una de las pocas opciones disponibles para intentar recuperar de algún modo su maltrecho prestigio internacional tras la derrota de Cuba (1898) y la pérdida definitiva del imperio de ultramar, y un modo de asegurar su status de potencia de segunda fila en el orden imperial europeo. Ciertamente, España se sabía en el fondo ajena a las profundas pasiones coloniales de otras potencias industriales, pero no por ello desistió de mantener sus aspiraciones en una región en la que durante más de 500 años había contado con enclaves territoriales ${ }^{9}$. Quizás fuera ese en verdad el único punto indiscutible de la apuesta española (la cercanía geográfica y las plazas de soberanía en Ceuta y Melilla), que le sirvieron para asegurar su precedencia sobre otros posibles competidores europeos. Al mismo tiempo, sin embargo, introduciría a la política exterior española en el juego de equilibrios diseñado por Inglaterra para coartar una presencia exclusiva de Francia en Marruecos y para proteger la libertad de circulación en el Estrecho.

De ese modo, los acuerdos internacionales firmados sobre Marruecos a comienzos del siglo XX pusieron de manifiesto, por una parte, la respuesta de la diplomacia europea ante los embates agresivos del Káiser y, por otra, el progresivo dominio e influencia que Francia comenzaba a adquirir en el Imperio marroquí. Si los primeros sirvieron para "desinteresar" finalmente a Alemania de Marruecos, sobre todo tras la firma del Convenio franco-alemán de 1911 — que otorgó a aquélla extensos territorios en el Congo-, los segundos confirmarían las dificultades de la estrategia defensiva de la diplomacia marroquí, cuyos anhelos internacionalistas se verían progresivamente amenazados por los acuerdos bilaterales firmados por Francia desde comienzos de siglo para despejar su dominio exclusivo en Marruecos (Acuerdo franco-

\footnotetext{
${ }^{8}$ Ningún gobierno español se habría resignado "a la ignominia de abandonar la costa sur del Estrecho de Gibraltar en manos de los franceses”, según el embajador británico en España, Maurice de Bunsen. (Bunsen to Sir Edward Grey, ministro de Asuntos Exteriores, 5 de diciembre de 1912, National Archives, Londres (NA), FO 185/1141).

${ }^{9}$ La expresión es de José María Jover Zamora, Política, Diplomacia y Humanismo popular. (Madrid: Turner, 1976), 138. Véase también Sebastian Balfour, The End of the Spanish Empire. (Oxford: OUP, 1997), 183-187.
} 
español de 1902, Declaración franco-británica de 1904) ${ }^{10}$. España acabaría ocupando en los mismos el papel de comparsa de los intereses británicos, aceptado a regañadientes por Francia.

El tejido jurídico que confirmó la dependencia colonial de Marruecos, por tanto, fue resultado directo de encontrados intereses internacionales que convirtieron la futura administración del país en un pulso entre sus diversos representantes. Se mantuvo, en primer lugar, la apariencia de la soberanía del Sultán sobre el territorio bajo un régimen de protectorado (algo similar a lo que había intentado Inglaterra en Egipto en 1882), en el que las potencias europeas se comprometían a ayudar al Sultán a introducir las reformas necesarias para la modernización del Imperio. Esta ficción jurídica revestida de entendimiento mutuo entre el Sultán y sus acreedores (en el prefacio del Tratado de marzo de 1912 se llegaba a decir que el Sultán había pedido la asistencia de las potencias europeas), se vio justificada por el agravamiento de las tensiones domésticas del país desde finales del siglo XIX, al que no eran ajenas las interferencias políticas, económicas y financieras de las potencias europeas. En segundo término, el tratado entre Francia y Marruecos y el convenio entre Francia y España confirmaron la división del Sultanato de acuerdo con los intereses de las potencias protectoras, reflejando la posición relativa de las mismas en dicha empresa. El Protectorado francés acumularía la mayor parte del territorio marroquí bajo administración exclusiva de Francia en nombre del Sultán y la Zona de influencia española se vería limitada a un pequeño hinterland en torno a los enclaves históricos de Ceuta y Melilla, dividida en su zona central por las montañas del Rif y completamente rodeada por el Protectorado francés en el sur. Tánger permanecería bajo un estatuto internacional que aseguraría la influencia de diversas potencias europeas (entre ellas, Italia) y la política de "puerta abierta" requerida por los intereses comerciales de los Estados Unidos.

Para que dicho proyecto funcionara con una mínima coherencia era indiscutible la necesidad de una cierta armonía entre las diversas potencias participantes ${ }^{11}$. La colaboración entre Francia y España, que de manera señalada había servido para

\footnotetext{
${ }^{10}$ Rashid Kabbani, Morocco: From Protectorate to Independence, 1912-56. (Washington: The American University, 1957), 26-37.

${ }^{11}$ Como afirma Chandler, la firma del Convenio con Francia había supuesto "un cambio fundamental" en el papel de España en Marruecos (James A. Chandler, "Spain and Her Moroccan Protectorate 18981927”, Journal of Contemporary History, 10/2, (1975), 301-322, 307).
} 
justificar la presencia española en el Sultanato, pasó así a convertirse en uno de los cimientos del futuro edificio colonial en Marruecos. Como se verá en las páginas que siguen, la realidad de las relaciones franco-españolas estuvo lejos de responder a dichas expectativas.

\section{LAS TENSIONES PROFUNDAS (1912-1918)}

Las previsiones de una colaboración entre Francia y España se vieron desmentidas por el carácter que adquirió la acción colonial de ambos países desde la misma firma del Tratado de Protectorado. Pueden distinguirse dos períodos en este progresivo distanciamiento de las relaciones franco-españolas. El primero vino señalado por la actitud inicial de Francia en Marruecos, a la que España respondió con una reciprocidad resentida y hostil (1912-1914). El segundo período se caracterizó por la ambigüedad de la postura española durante la Gran Guerra, ante la que Francia reaccionó de modo airado y ofendido (1914-1918). Ambas etapas acabaron con la idea de una sintonía entre las potencias "protectoras" en Marruecos, que en el futuro actuarían más como rivales que como socias.

\section{Los antagonismos iniciales (1912-1914)}

La influyente mentalidad colonial francesa y su confianza en el cumplimiento de su destino africano, tan diferente de la fragilidad del africanismo español, hizo proceder a los representantes de la Tercera República en Marruecos con una visión y aplomo destacados, en los que la presencia de un vecino necesitado no pasó de considerarse un inconveniente inevitable. El desenvolvimiento y la soltura de las autoridades francesas estaban, de este modo, poco menos que destinados a provocar la envidia y el enardecimiento de sus homólogos españoles, en el papel de pariente pobre de Francia en Marruecos.

En la reacción irritada y hostil de España ante los exitosos comienzos de la acción francesa participaron una serie de factores, algunos de carácter africano y otros de carácter peninsular. Entre los primeros, existía una frustración inicial y patente en 
numerosos mandos militares del Ejército de África, que responsabilizaban a Francia de haber truncado las esperanzas españolas al otro lado del Estrecho ${ }^{12}$. A ello se sumaba la mentalidad frecuente entre algunos miembros de la oficialidad colonial, que veían en Marruecos la oportunidad de devolver al Ejército el prestigio y la dignidad perdidos en Cuba, una postura que contribuyó a difundir la idea de que la Zona española era un espacio reservado para la regeneración nacional, en mayor medida que un enclave estratégico cuyo mantenimiento dependía de la colaboración con otras potencias ${ }^{13}$. Desde una perspectiva peninsular, la recuperación progresiva de la influencia del Ejército en la escena pública desde comienzos del siglo XX sirvió también para avanzar y consolidar la imagen de Marruecos como una suerte de feudo militar, destinado al control de la autoridad castrense en mayor medida que a la supervisión del poder civil. Otras circunstancias domésticas, como la inestabilidad creciente de los gobiernos de la Restauración y la escasa continuidad de la política colonial marroquí no hicieron sino confirmar estas tendencias ${ }^{14}$.

Un resultado de esta combinación de factores fue que, lejos de conducirse como una potencia aliada, España inició su acción colonial en el territorio de una manera “ensimismada”. En el terreno administrativo, el Jalifa de la Zona española recibió desde el comienzo consideración y rango de autoridad soberana, en mayor medida que condición de simple representante del Sultán, algo que causó una fricción evidente con las autoridades francesas ${ }^{15}$. En el terreno militar, a cada nuevo avance francés en la región de Fez (capital del imperio) respondió una iniciativa inmediata en las cercanías de Melilla (centro de la escalada militar española), en una sucesión de impulsos y conquistas recíprocos que manifestaron una ausencia señalada de consulta y acuerdo entre ambos socios coloniales y, particularmente en el caso de España, el objetivo de llegar cuanto antes a los límites de la zona delimitada en 1912 con el fin de "marcar" el

\footnotetext{
12 El Convenio de 1904, como se sabe, redujo significativamente la extensión de la zona española acordada en 1902.

${ }^{13}$ Véase Sebastian Balfour, "La conformación de un ejército intervencionista, 1898-1923", en Francisco J. Romero y Angel Smith (eds.), La agonía del liberalismo español. De la revolución a la dictadura, 1913-1923, (Granada: Comares, 2014), 255-272, 266-267.

${ }^{14}$ Carolyn P. Boyd, La politica pretoriana en el reinado de Alfonso XIII, (Madrid: Alianza, 1990), 221.

${ }^{15}$ El Residente General francés, mariscal Lyautey, llegaría a afirmar años después que las relaciones franco-españolas en Marruecos se habían visto "envenenadas" desde el inicio por esta pretensión de las autoridades españolas (Lyautey a Pierre de Cuverville, agregado militar de la Embajada francesa en España, 4 de marzo de 1924, Centre des Archives Diplomatiques de Nantes, Maroc (CADN-M), CD243).
} 
territorio antes de la llegada de las tropas francesas ${ }^{16}$. Una diferencia evidente entre ambos empeños era que mientras Francia aseguraba su autoridad y control a pasos agigantados y de manera aparentemente impasible, España completaba adquisiciones mucho más reducidas con el doble de esfuerzo. Otra diferencia importante era que la zona de influencia española, enteramente rodeada por el Protectorado francés al sur, estaba más expuesta y necesitada de cooperación para consolidar su dominio, sobre todo en el Rif.

El ritmo, la envergadura y la escala del progreso francés en el Sultanato superaron, por tanto, ampliamente y desde el comienzo, los intentos mucho más limitados de sus vecinos españoles. Otras razones de este desigual desempeño colonial se debían a la geografía compleja de la zona española, a la inexistencia de señores feudales cuya amistad o soborno pudiera garantizar el dominio sobre grandes extensiones de territorio, como ocurría en el Protectorado francés, o a la escasez de recursos naturales, mucho más pronunciada en la zona española que en la francesa ${ }^{17}$. Motivos adicionales de estas disparidades se remontaban a la escasa coherencia de la política colonial española, tan alejada de la dirección sostenida del Quai d'Orsay, y al modo en que se reflejaba en la ejecución de las operaciones militares. Las serias dudas, vacilaciones y admoniciones a los mandos españoles en Marruecos para que no se produjeran bajas que pudieran repercutir en la opinión nacional, tan sensible tras los acontecimientos de 1909, fue una experiencia paralizante que el primer Residente General francés, mariscal Lyautey (1912-1925), nunca experimentó en el mismo grado que sus homólogos españoles, los Altos Comisarios Alfau (1912-1913) y Marina (19131915). Ello determinó, por parte española, unas operaciones militares que, aunque emularon los avances franceses, fueron siempre limitadas, enormemente cautas y poco inclinadas a la explotación del éxito. En definitiva, muy diferentes de la práctica militar francesa ${ }^{18}$.

\footnotetext{
${ }^{16}$ Iniciativas que, según el Presidente del gobierno español, José Canalejas, estaban inspiradas por "los celos" de los militares españoles ante los avances franceses (John Rennie, secretario de la Embajada británica en España, a Grey, 30 de julio de 1911, NA FO 413/55).

${ }^{17}$ Estas diferencias se exploran en Jean-Marc Delaunay, Méfiance cordiale. Les relations francoespagnoles de la fin du XIXe siècle à la Première Guerre mondiale (Volume 2). (París: L'Harmattan, 2010), 524-576 y 586-695.

${ }^{18}$ Véase William A. Hoisington Jr., Lyautey and the French conquest of Morocco. (Basingstoke: Palgrave Macmillan, 1995), 41-55.
} 
Los recursos disponibles del Ejército colonial, la experiencia y formación de sus cuadros de mando, la instrucción de las tropas y la operatividad de las llamadas unidades indígenas, todas muy superiores una vez más entre las columnas francesas que entre las unidades españolas, confirmaron también el carácter diferencial de la colonización de ambos países, permeada desde sus primeros pasos por la hostilidad española ante la evidencia del éxito francés. El mariscal Lyautey, que había iniciado su gestión colonial con muestras de simpatía no exentas de paternalismo y condescendencia hacia sus vecinos, pronto rectificó su actitud y dio prioridad también a los objetivos estrictamente militares franceses.

\section{La Primera Guerra Mundial (1914-1918)}

Los orígenes conflictivos de las relaciones franco-españolas en Marruecos se vieron agravados decisivamente durante la Primera Guerra Mundial, en la que la neutralidad oficial española adoptada en la Península no se reflejó del mismo modo al otro lado del Estrecho. Indudablemente, una buena parte de los mandos militares españoles albergaba simpatías por la causa de las potencias centrales, en buena medida debidas a la admiración por el ejército prusiano — vencedor en Sedán (1870) —, a cuya eficacia y organización debía aspirar el futuro ejército español, en opinión de muchos de ellos. Dichas simpatías se sumaban en la zona española de Marruecos a los agravios comparativos con Francia, en un contexto y un entorno en el que la autoridad militar gozaba de una influencia muy superior a la de los representantes civiles.

Fuera ello resultado de la actitud altanera del Ejército ante los cada vez más volátiles gobiernos liberales de comienzos del siglo XX o producto del pragmatismo del poder civil, que podía evitarse los gastos de una administración civil paralela al ofrecer a los militares amplias áreas de responsabilidad en Marruecos, el hecho es que la zona española se convirtió en una región de extendidas simpatías germanófilas ${ }^{19}$. De ello eran conscientes no solo los gobiernos de Madrid, en buena medida responsables de la independencia de criterio que habían adquirido las autoridades coloniales, sino también

\footnotetext{
${ }^{19}$ Véase Sebastian Balfour, Abrazo mortal: De la guerra colonial a la Guerra Civil en España y Marruecos (1909-1939) (Barcelona: Península, 2002), 46-51.
} 
los Altos Comisarios del Protectorado, en ocasiones partícipes de estas tendencias ${ }^{20}$. La conflictiva realidad de la zona española, donde la expansión colonial se situó desde el comienzo en la órbita de las campañas militares, contribuyó a confirmar la preeminencia del poder militar sobre el civil y, del mismo modo, su particular postura ante la Gran Guerra.

Las muestras de dicha parcialidad hacia la causa alemana se manifestaron primeramente en la marco de la resistencia nativa. Tanto en la zona oriental de Melilla como en la occidental de Ceuta, las armas españolas habían encontrado prontamente jefes locales de cierto prestigio y autoridad, cuya sagacidad y astucia habían convencido a los mandos militares de la necesidad de atraerlos para facilitar la expansión española. Las instrucciones recibidas de los gobiernos de Madrid, estrictamente severas en lo relativo al uso de tropas, favorecían los tratos con dichos jefes, entre los que destacaba la figura del Raisuni en la zona occidental y la de Abd el Malek en la zona oriental ${ }^{21}$. El Raisuni, dominador de las cabilas situadas en la región de Yebala, había sido una figura decisiva en la expansión inicial al oeste del protectorado. Las relaciones con Abd el Malek se centraban en sus actividades en los dominios en el Rif, en la zona de contacto con la zona francesa.

Los enlaces con dichos caudillos experimentaron una transformación progresiva desde el comienzo de la Gran Guerra, con la llegada a Marruecos de agentes alemanes interesados en establecer contacto con la resistencia local y de soliviantarla en contra de sus autoridades “protectoras". Esta estrategia alemana, parte de un plan más vasto que aspiraba a la subversión general de los imperios coloniales de la Entente en el norte de África, introdujo elementos nuevos en las relaciones entre los mandos españoles y las cabilas del territorio ${ }^{22}$. Por una parte, la neutralidad oficial de la zona española facilitó la

\footnotetext{
${ }^{20}$ Para el Alto Comisario Marina, por ejemplo, la neutralidad colocaba a los mandos españoles "en una situación difícil por las complicaciones que pudiera acarrearnos cualquier ligereza" (Marina al gral. Gómez Jordana, Cte. Gral. de Melilla, 14 de agosto de 1914, Archivo General Militar de Madrid, Marruecos, (AGMM-M), rollo 744, leg. 5/12).

${ }^{21}$ Se continuaba así una tradición iniciada con los tratos con el Roghi en Melilla a comienzos de siglo, una oportunidad perdida, de acuerdo con algunos autores, que determinó el carácter de la futura acción española. Véase José Manuel Allendesalazar, La diplomacia española y Marruecos, 1907-1909, (Madrid: AECI, 1990), 126.

22 Sigue siendo indispensable para el periodo Charles R. Pennell, "A critical investigation of the opposition of the Rifi confederation led by Muhammed bin'Abd al-Karim al-Khattabi to Spanish colonial
} 
entrada y las iniciativas de los agentes alemanes, expulsados del Protectorado francés desde el comienzo de la guerra. Por otra, la propaganda y los envíos de dinero y material de estos últimos aspiraban a fomentar la rebelión entre las tribus en la zona francesa, a fin de crear una situación comprometida que evitara el envío de refuerzos al escenario continental. La actitud de las autoridades españolas ante dichos manejos se convertiría en la razón fundamental de que la cooperación en Marruecos desapareciera casi enteramente del horizonte colonial en los años siguientes, anticipando las circunstancias que rodearían el desastre de Annual en $1921^{23}$.

Las injerencias alemanas probaron, en primer lugar, que la zona internacional de Tánger, desde donde se coordinaron muchas de las iniciativas anteriores, podía convertirse en un área de interferencia extranjera de consecuencias imprevisibles, tanto para el Protectorado francés como para la zona española ${ }^{24}$. Por otra parte, las actividades alemanas también revelaron la indiferencia benevolente de las autoridades españolas, que en último caso parecían creer que la potencia más afectada por estas actividades sería Francia, algo que muchos oficiales españoles observaban con cierta satisfacción íntima. Los peligros de dicha interpretación fueron repetidamente denunciados por el propio Alto Comisario español, general Gómez Jordana (19151918), para quien resultaba obvio que la propaganda alemana y la incitación a la rebelión contra las autoridades francesas se volvería antes o después contra el dominio español $^{25}$.

La reacción de las autoridades militares francesas ante lo que percibían como una indisimulada connivencia de los mandos españoles con las actividades alemanas fue, como no podía ser menos, tajante, sobre todo en la persona del mariscal Lyautey. La Gran Guerra había puesto a Lyautey en una situación verdaderamente insostenible, requerido incesantemente por su gobierno a enviar fuerzas coloniales al frente europeo

expansion in northern Morocco, 1920-1925, and its political and social background", vol. 1, (Tesis Doctoral, Universidad de Leeds, 1979), 151-201.

${ }^{23}$ Daniel Rivet, Lyautey et l'institution du protectorat français au Maroc, 1912- 1925, vol. 3, (París: L'Harmattan, 1988), 161 y ss.

${ }^{24}$ Véanse Juan Carlos Pereira Castañares, "El contencioso de Tánger en las relaciones hispano-francesas (1923-1924)", en Españoles y franceses en la primera mitad del siglo XX. (Madrid: CSIC, 1986), 303322, 303-305 y, para todo el periodo, Francisco de Asís Serra y Bonastre, Tánger, 1916-1924, (Granada: Almed, 2017).

${ }^{25}$ Gral. Gómez Jordana a Cte. Gral de Ceuta, Gral. Milans del Bosch, 21 de septiembre de 1915, AGMM-M, rollo 357, legajo 214/3. 
y, al mismo tiempo, obligado a mantener el control militar sobre el territorio ${ }^{26}$. La solución ideada por Lyautey, "la coraza externa", permitió el mantenimiento de fuerzas expedicionarias en los límites de la expansión francesa y el vaciamiento progresivo de las tropas en las zonas ya dominadas del interior, en una arriesgada maniobra que dejaba el dominio francés en Marruecos en una situación precaria ${ }^{27}$. La enorme tensión y zozobra de Lyautey en aquellos años —en los que advirtió en diversas ocasiones de la posibilidad del derrumbamiento del Marruecos francés- se vio incrementada por los levantamientos liderados por caudillos de la zona francesa, que probablemente vieran en la guerra una oportunidad para deshacerse del yugo colonial. Reacio a concebir dichas acometidas como pruebas de hostilidad contra Francia, Lyautey tendió a interpretarlas como resultado de la propaganda alemana y de la actitud ambigua de las autoridades españolas, a las que culpó directamente de estas dificultades añadidas ${ }^{28}$. Los escritos del Mariscal no dejaron lugar a dudas sobre la profunda huella que dichas circunstancias imprimieron en su resolución final de rechazar en el futuro cualquier intento de cooperación con España en Marruecos, una decisión que resultaba en principio mucho más perjudicial para España que para Francia, y cuyas consecuencias fatales no tardarían en hacerse patentes en los años siguientes.

\section{DE AVANCES Y RESISTENCIAS (1918-1921)}

El final de la Primera Guerra Mundial y el Tratado de Versalles sirvieron para consolidar aún más la postura de Francia en Marruecos y para poner aún más en evidencia la subordinación de la postura española. Si bien es cierto que las potencias vencedoras resistieron algunas de las peticiones más radicales de la diplomacia francesa tras la guerra (la inclusión de Tánger en zona francesa, por ejemplo), también lo fue que

\footnotetext{
${ }^{26}$ Hoisington, Lyautey, op. cit., 187-190.

27 Véase Moshe Gershovich. French Military Rule in Morocco: Colonialism and Its Consequences (Londres: Frank Cass, 2000), 107-111.

28 "Durante cuatro años - afirmaría Lyautey al final de la guerra - los alemanes y sus agentes han tomado por base de sus ataques incesantes contra el Protectorado francés la zona española...bajo la mirada cómplice, benevolente o por lo menos indiferente de las autoridades españolas". Lyautey a Stéphen Pichon, Ministro de Asuntos Exteriores, 13 de julio de 1919, Archives du Ministère des Affaires Étrangères et du Développement International, Maroc, 1917-1940 (MAEDI-M), leg. 189.
} 
Francia salió fortalecida de la prueba y engrandecida en sus responsabilidades (derechos mineros, régimen de capitulaciones, Banco de Marruecos). En sus artículos 141 a 146, el Tratado de Versalles reflejó por tanto las nuevas prerrogativas del Protectorado francés y el paralelo declive ante las mismas de la Zona española ${ }^{29}$.

\section{Berenguer y Lyautey}

En esta última, el fin del conflicto coincidió con la llegada de un nuevo Alto Comisario, el general Dámaso Berenguer (1918-1922), que sustituyó al malogrado general Gómez Jordana, fallecido en las últimas semanas de la guerra. Berenguer, cuarto Alto Comisario español desde el inicio del Protectorado, trató de imprimir, quizás por vez primera, una nueva dirección a las relaciones franco-españolas en Marruecos, para lo que no escatimó muestras de cortesía y deferencia hacia las autoridades vecinas y, en especial, hacia el mariscal Lyautey. La tarea no era sencilla, ya que se habían acumulado una sucesión de malentendidos y reticencias entre ambas potencias que no eran fáciles de disipar.

En años anteriores, Lyautey había visitado España y se había entrevistado con el rey Alfonso XIII, a quien había expresado y de quien había recibido los mejores deseos para la cooperación franco-española en Marruecos. Lyautey guardó siempre un recuerdo memorable de aquella visita y una simpatía duradera hacia el monarca español que, sin embargo, las sucesivas etapas de la acción colonial prontamente contribuyeron a enfriar $^{30}$. La dificultad más grande que afrontaba Berenguer, como se dijo, se debía a las profundas secuelas dejadas por la Gran Guerra en las relaciones franco-españolas y, en concreto, a la incredulidad, la exasperación y la profunda decepción que la actitud de las autoridades españolas habían causado en el mariscal Lyautey. No ajeno a las exageraciones un tanto melodramáticas ni a las expresiones desmayadas y superlativas, Lyautey, cuya figura dominaba la administración colonial francesa en Marruecos de un modo mucho más preponderante que la del Alto Comisario en la zona española, parecía sinceramente afectado por lo que él consideraba la "traición" de las autoridades

\footnotetext{
${ }^{29}$ Puede consultarse la monumental obra de David Hunter Miller, My diary at the Conference of Paris: with documents. (Nueva York: 1924), vol. X, 313-317 y vol. XVI, 55-60 y 71-73.

${ }^{30}$ Lyautey recordaría a menudo este encuentro “encantador” en 1913. Rivet, Lyautey..., op. cit., 152-153.
} 
coloniales españolas durante la Gran Guerra. La reparación de dichos daños no iba a suponer una labor sencilla ${ }^{31}$.

De cualquier modo, Berenguer comenzó su andadura como Alto Comisario consultando con los generales franceses y con Lyautey los planes de la futura acción militar de España en Marruecos y las posibles eventualidades que pudieran desarrollarse a la largo de la misma. Habiéndose detenido la mayoría de las operaciones en la zona española durante la guerra, el nuevo Alto Comisario estableció como prioridades la consolidación del dominio de la región occidental, por una parte, y el inicio de la penetración en el Rif en la zona oriental, por otra. Los impedimentos más evidentes para estos designios nacían de la revitalización de la resistencia nativa, que se había visto espoleada por los recursos y la propaganda alemana durante la guerra. En la región occidental, la posición de El Raisuni y su dominio sobre las cabilas cercanas a Tetuán le habían convertido en una figura irremplazable para asentar el control colonial español. Algo similar ocurría en la región oriental, donde el eclipsamiento de Abd el Malek tras la guerra se vio prontamente reemplazado por la emergencia de otro líder que acabaría unificando la resistencia rifeña, Abd el Krim el Jatabi ${ }^{32}$.

Las dificultades a las que se enfrentaba el Ejercito de África en ambos territorios no se debían tan solo a la actitud ambigua de estos caudillos, sino también al propio sistema de consolidación de la penetración militar. Entorpecido por la dificultad de transporte, ausencia de carreteras y medios de comunicación, el avance de las tropas españolas se había traducido en el emplazamiento de guarniciones sucesivas rodeadas casi enteramente por cabilas y tribus a cuyos jefes se pagaba un subsidio para mantener su actitud amistosa y para facilitar avances sucesivos. Dicho sistema podía considerarse resultado de una confluencia de factores, entre los que primaban las economías sucesivas en el presupuesto militar desde comienzos de siglo, cada vez más destinado al pago exclusivo de salarios debido al recargamiento de las escalas y cada vez más reducido en la inversión en material y equipamiento, y también el deseo de los

\footnotetext{
${ }^{31}$ Hoisington, Lyautey..., op. cit., 187-190. Lyautey llegó a sugerir a su gobierno pedir “cuentas de sangre" a España por su actitud durante la Gran Guerra. Lyautey a Pichon, 4 de julio de 1919, CADN-M, cMC6.

${ }^{32}$ Sobre los caudillos de la zona española puede verse Carlos-Federico Tessainer y Tomasich, El Raisuni. Aliado y enemigo de España. (Málaga: Algazara, 1998) y María Rosa de Madariaga, Abd el-Krim el Jatabi. La lucha por la independencia. (Madrid: Alianza Ensayo, 2009). Abd el Malek continuó ofreciéndose a apoyar la causa española y a liderar la oposición a Abd el Krim hasta su muerte en 1924.
} 
gobiernos de Madrid de completar avances sin enfrentamientos serios que pudieran inquietar a la opinión pública ${ }^{33}$.

El problema de un sistema basado en el pago de subsidios, como habían identificado algunas autoridades militares, era que, si no se completaba con una atenta y vigilante presencia militar con asiduos y crecientes contactos que permitieran la creación de intereses comunes, dejaba a las unidades militares avanzadas a merced de los líderes locales, que siempre podían requerir más medios para la protección de éstas o incluso favorecer la resistencia a fin de asegurar su sustento. Berenguer se mostró desde el comienzo opuesto a dicho sistema en ambas Comandancias Generales, aunque no se decidió a suprimirlo ${ }^{34}$.

En general, puede decirse que el mariscal Lyautey recibió con agrado las consultas iniciales de Berenguer - “el único español inteligente que había estado nunca en Marruecos" ${ }^{\prime 3}$ _, aunque no era mucho lo que podía extraerse de las mismas, más allá de un intercambio de información. El mismo Lyautey hacía frente a problemas bastante diferentes a los de la zona española, centrados en la ocupación de Taza y el avance hacia la zona suroriental del Protectorado francés. Mientras para España las prioridades pasaban, por tanto, por una extensión del dominio militar hacia el sur del territorio en dirección a la zona de contacto con los puestos franceses, para Francia, que ya había conseguido antes de la guerra el sometimiento de las grandes llanuras del interior a través de contactos duraderos con los jefes locales respaldados por una activa presencia militar (la "mancha de aceite" de Lyautey), la prioridad era la sumisión de la zona de Taza y el contacto con la frontera argelina.

\section{El avance hacia el Rif}

Las circunstancias que rodearon el avance hacia el Rif pusieron de manifiesto no solo la idiosincrasia del Ejercito de África, ya agitado por entonces por las diferencias entre junteros y africanistas, sino también las condiciones cada vez más delicadas en las

\footnotetext{
${ }^{33}$ Stanley G. Payne, Politics and the Military in Modern Spain, (Stanford: SUP, 1967), 123-128.

${ }^{34}$ Berenguer a Cte. Gral de Melilla, Gral. Aizpuru, 19 de agosto de 1919, AGMM-M, rollo 97, leg. 20/13.

${ }^{35}$ Sir Robert Clive, Cónsul General en Tánger, a Sir Austen Chamberlain, Ministro de Asuntos Exteriores, 12 de marzo de 1925, tras entrevista con Lyautey, NA FO 371/11083.
} 
que esta expedición militar se vería progresivamente envuelta. Dicho avance requería, en opinión de Berenguer, una estabilización previa de la situación en la región occidental, con el fin de evitar la apertura de dos frentes simultáneos. Berenguer decidió, por tanto, establecer unas bases más sólidas que garantizaran el equilibrio de la zona occidental antes de iniciar operaciones de importancia en el frente oriental. Para ello, resolvió acometer la sumisión y pacificación de la comarca de Yebala, aquella sobre la que el jerife Raisuni tenía más influencia, con el fin de acorralar al caudillo y obligarle a someterse a las autoridades españolas en términos claros y categóricos ${ }^{36}$. Dichas precauciones no se vieron completadas por planes conjuntos entre los jefes militares españoles y franceses, cuyos contactos se limitaron a señalar las prioridades de sus avances en las zonas respectivas. Dicho de otro modo: el inicio de la penetración española en el Rif se llevó a cabo sin una coordinación previa y explícita con las autoridades francesas, algo que dada la experiencia previa en Marruecos no parecía particularmente relevante, pero que en el transcurso de la misma se convertiría en una lacra decisiva.

El progreso de las operaciones en el Rif pronto reveló las carencias de las armas españolas $\mathrm{y}$, particularmente, la frágil estructura de su dominio a medida que se adentraban en el territorio. Parte fundamental de estos obstáculos la constituía la labor realizada por Abd el Krim, líder de la tribu de los Beni Urriagel, que había sido previamente empleado por la administración colonial española y cuya familia había sido una de las primeras en recibir subsidios en la bahía de Alhucemas, entrada natural al Rif por mar. Al igual que el Raisuni, la suerte de Abd el Krim se había visto decisivamente influida por la Gran Guerra, durante la cual sus actividades pro-alemanas habían causado ciertos sonrojos e incomodidad a las autoridades españolas. Con el fin de apaciguar las protestas francesas a este respecto, fue encarcelado en Melilla, probablemente más como un escarmiento temporal que como una censura solemne a sus actos. Dichas represalias, sin embargo, tuvieron un efecto devastador en las simpatías de Abd el Krim, que poco después de su encierro puso fin a todas sus relaciones con las autoridades de Melilla y regresó al Rif decidido a oponerse al avance español ${ }^{37}$.

\footnotetext{
${ }^{36}$ La situación se describe en detalle en Pennell, $A$ Critical..., op. cit., vol. 1, 211 y ss.

${ }^{37}$ Madariaga, Abd el-Krim..., op. cit., 152-153.
} 
En su labor de incitación a la resistencia entre las tribus, Abd el Krim se sirvió de la colaboración de enlaces extranjeros, cuya presencia en el Rif probablemente se remontara a los contactos del jefe rifeño durante la Gran Guerra. Entre ellos se encontraban agentes y desertores que le facilitaron no solo la adquisición de material de guerra - algo que Abd el Krim podía conseguir a través del frecuente contrabando de munición y cartuchos proveniente del propio Ejército de África-, sino también la experiencia de su uso y la coordinación de las relaciones entre las diversas tribus. El grado en que dichos colaboradores extranjeros contribuyeron a revitalizar la resistencia en el Rif continúa siendo un debate inacabado entre los historiadores, aunque existen pocas dudas sobre sus actividades, conocidas incluso por las autoridades españolas ${ }^{38}$.

No significa esta hipótesis sugerir, por tanto, que el renovado ímpetu de la resistencia rifeña ante la llegada de las tropas españolas se debiera mayoritariamente a la colaboración y a la supervisión de agentes extranjeros. El Rif había sido durante siglos una región hostil a la penetración foránea (e incluso al mismo Sultán), y la presencia cada vez más cercana de soldados españoles estaba destinada a producir una reacción defensiva y generalizada entre las tribus. La colaboración de agentes extranjeros con Abd el Krim probablemente contribuiría a dar mayor entereza y solidez a dicha agitación. Y, ciertamente, la coordinación de la resistencia en el Rif se hizo más evidente a medida que las columnas del Ejército de África se adentraban en el territorio.

Los avances en el Rif tenían como objetivo final la ocupación de la bahía de Alhucemas, posición cuyo dominio aseguraba la llegada ininterrumpida de refuerzos por mar para las tropas avanzadas y la previsible expansión y conquista de la región. Los planes de Berenguer para conseguir este objetivo no eran desconocidos para Lyautey, que apreció la lógica de los mismos y también los escollos a los que se enfrentaban ${ }^{39}$. La realización de dichos planes, sin embargo, dependía del quehacer de los subordinados de Berenguer, y en particular, del Comandante General de Melilla, general Manuel Fernández Silvestre, cuyo historial militar demostraba una cierta independencia

\footnotetext{
${ }^{38}$ Pennell, A Critical..., op. cit., 226 y ss. Quizás la exposicion más completa de la situación se encuentre en Mohamed TahTah, "Entre pragmatisme, réformisme et modernisme: le rôle politico-religieux des Khattabi dans le Rif (Maroc) jusqu'à 1926”. (Tesis doctoral, Universidad de Leiden, 1995), 59-79.
}

\section{${ }^{39}$ Lyautey a Aristide Briand, Ministro de Asuntos Exteriores, 26 de julio de 1921, MAEDI-M, leg. 620.}


de criterio con respecto a sus superiores, bastante frecuente por otra parte entre la oficialidad de Marruecos ${ }^{40}$.

El ritmo pujante que Silvestre imprimió al avance español y los crecientes obstáculos que éste encontró fueron objeto de una entrevista frecuentemente citada entre los historiadores, que tuvo lugar a comienzos de junio de 1921 y durante la cual, al parecer, se acordó detener o aminorar la progresión en el Rif hasta que la situación de las cabilas que rodeaban a las tropas españolas se hubiera sosegado y hasta que Berenguer hubiera tenido tiempo de completar las operaciones en el frente occidental, próximas a su finalización ${ }^{41}$. El progreso de las tropas españolas en el Rif en aquel momento, como se sabe, descansaba en el establecimiento de una serie de posiciones avanzadas, escalonadas hacia el interior del territorio y abastecidas desde emplazamientos militares más extensos y consolidados desde los cuales, y a través de rutas tan solo abiertas a soldados de a pie y a ganado, se les proporcionaba municiones y víveres. Sin duda alguna, tal sistema de avance era precario en muchos de sus aspectos, entre los que se incluían las frágiles comunicaciones entre las posiciones, que transcurrían entre los escarpados riscos del Rif, la relativa escasez de material y equipamiento de que disponían las unidades — muchas de ellas compuestas por soldados peninsulares de reemplazo que simplemente esperaban el permiso que les devolviera a la Península-, y la dudosa fidelidad de las unidades indígenas que acompañaban a las columnas españolas.

La deducción de que, en tal estado de cosas, los sucesos de Annual eran poco menos que inevitables resulta, sin embargo, arriesgada. De acuerdo con los planes acordados en junio de 1921, a los que Silvestre dio su aprobación, y a los que el Estado Mayor de Berenguer prestó particular atención, los refuerzos y recursos con los que contaba Silvestre, si no adecuados para una ofensiva, sí resultaban suficientes para la situación de calma y reagrupamiento que se le había pedido y que él había aceptado tras su entrevista con el Alto Comisario. Lo que acabaría trastocando completamente el

\footnotetext{
${ }^{40}$ De acuerdo con el embajador británico en España, Silvestre era un general "de frontera" (Bunsen a Grey, 25 de abril de 1911, NA FO 413/54). Una biografía reciente (y abiertamente elogiosa) en Vicente Fernández Riera, De Cuba a Annual. Vida y muerte del General Silvestre (1871-1921). (Madrid: Almena, 2018).

${ }^{41}$ La entrevista tuvo lugar tras la pérdida de la posición de Abarrán, ocupada el 1 junio de 1921 y recuperada poco después por las harcas rifeñas. Fue inicialmente relatada por el periodista Víctor Ruíz Albéniz, España en el Rif. (Melilla, Ayuntamiento de Melilla, 1994, $1^{\text {a }}$ ed. 1921), 213.
} 
progreso de las tropas españolas en el Rif no fueron tan solo los nuevos avances de Silvestre a comienzos de julio de 1921, de justificación debatible, sino, particularmente, la organización, la coordinación y la determinación de las harcas de Abd el Krim, que desconcertaron a los jefes militares españoles, los condujo progresivamente hacia una situación sin salida en las posiciones más avanzadas y acabó provocando un pánico desatado y transmitido de posición a posición y que no se detuvo hasta llegar a Melilla. Las primeras escaramuzas que señalaron el comienzo del desastre de Annual, por tanto, tuvieron como denominador común la sorpresa y el desconcierto de los jefes militares españoles ante los recursos, la coordinación de movimientos y la continuidad de estrategias de las harcas de Abd el Krim, que aprovecharon la delicada tesitura de las posiciones españolas para rodearlas, sitiarlas $\mathrm{y}$, finalmente, y casi metódicamente, ocuparlas $^{42}$.

Los elementos que contribuyeron, por tanto, a fortalecer, unificar y a dar una firme coordinación a la resistencia rifeña ante el avance español, muchos de ellos derivados del contexto internacional marroquí (además del genio organizativo de Abd el Krim) se encontraron ya presentes en los orígenes del desastre de Annual. Tan solo cuando se puso de manifiesto que el enemigo al que hacían frente las tropas españolas estaba preparado y dirigido de una manera eficaz y solvente, tomó cuerpo entre los mandos españoles la idea de una retirada inevitable, iniciada de manera progresiva y limitada, que acabaría despertando el odio contenido y la hostilidad de las cabilas circundantes y desencadenando el pánico entre soldados y oficiales españoles. En cuestión de días, se produjo el colapso de la Comandancia General de Melilla y el derrumbamiento del dominio español en la región desde $1912^{43}$.

\footnotetext{
${ }^{42}$ Una de las crónicas más detalladas del desastre en Eduardo Pérez Ortiz, De Annual a Monte Arruit, (Melilla, 1923), 25 y ss. Sobre la pretendida inevitabilidad del desastre, véase Balfour, Abrazo..., op. cit., $52-82$.

${ }^{43}$ Uno de los factores determinantes de la hecatombe, según todas las crónicas militares, fue el uso de artillería por parte de los rifeños contra las posiciones de Igueriben y de Annual. Las harcas rifeñas se habían apoderado de artillería española tras la caída de Abarrán, y su utilización experta contra Igueriben y Annual constituyó un elemento crucial del pánico inicial, que solo podía deberse, según estas crónicas, a la presencia de desertores extranjeros entre las tribus. (Pennell, A Critical..., op. cit., 297 y ss.).
} 


\section{LA GUERRA DEL RIF Y EL ACABAMIENTO DEL REGIMEN LIBERAL}

\section{(1921-1923)}

El desastre de Annual y la consiguiente guerra del Rif supusieron un desafío formidable para el ya más que maltrecho régimen liberal en España. La pérdida de todas las posiciones de la región oriental de la zona española (Melilla estuvo cerca de perderse también), no solo puso en cuestión la identidad colonial de España sino también la capacidad de los diversos gobiernos que se sucedieron al frente del país para responder a los compromisos internacionales adquiridos en 1912.

\section{El gobierno Maura (agosto de 1921-marzo de 1922)}

Enfrentado con la peor derrota colonial en la historia del Ejército español, el gobierno de concentración nacional presidido por Antonio Maura —el segundo gobierno de estas características tras el gabinete que afrontó la crisis de 1917—optó prontamente por mantener al general Berenguer al frente de la Alta Comisaría, a la vez que iniciar una acelerada movilización de tropas para enviarlas al otro lado del Estrecho.

Que esta recluta general no diera lugar a una oposición popular generalizada en la Península se debió a varios motivos, entre los que pueden destacarse la suerte incierta de los soldados españoles que aún continuaban su penosa retirada hacia Melilla y a los que los nuevos refuerzos se suponía que podían salvar; el decreto de movilización de los soldados de cuota, a los que se denegó la exención del servicio militar y que pasarían a unirse a las tropas de reemplazo, y el férreo control sobre la Prensa, al que se unió una campaña patriótica protagonizada por ayuntamientos, organizaciones locales e instituciones religiosas. El relativo aquietamiento de las fuerzas radicales de la izquierda, particularmente tras la represión intensa que había sufrido la CNT en Barcelona en años anteriores, probablemente ayudó a explicar también la aparente magnanimidad del espíritu público en los primeros momentos tras el desastre ${ }^{44}$.

Salvado el primer escollo, el gobierno de Maura, con Juan de la Cierva en el Ministerio de la Guerra, procedió a aprobar el plan inicial de Berenguer para la

\footnotetext{
${ }^{44}$ Véase María Gárate Bajo, "Las campañas de Marruecos y la opinión pública. Una puesta al día", Hispania, 79, 263 (2019), 727-756.
} 
reconquista militar, que pasaba por la recuperación decidida del territorio perdido en Marruecos con el fin de devolver cuanto antes a las tropas españolas a las cercanías del Rif, preferiblemente antes del asentamiento del crudo invierno marroquí. El mariscal Lyautey, que se vio sorprendido ante el desarrollo y la magnitud de la derrota española, fue mantenido al corriente de dichos planes, que él consideró acertados, aunque su preocupación principal por entonces consistía en evitar la repercusión de los acontecimientos del Rif en la zona francesa. Comprometido en el avance hacia Taza, lo último que deseaba el Residente General francés eran dificultades paralelas que atrasaran sus operaciones, que también esperaba a concluir antes del invierno ${ }^{45}$.

En dichas circunstancias, y tras el reagrupamiento de refuerzos en Melilla, los avances de las tropas españolas fueron ciertamente constantes. Para octubre de 1921, el Ejército colonial había recuperado ya las guarniciones más importantes (Nador, Monte Arruit) y para diciembre de 1921 sus unidades avanzadas habían llegado de nuevo a los aledaños del Rif, completando seis meses de progresos ininterrumpidos. La continuidad de los planes de Berenguer se mantuvo, como muchos habían hecho ya notar, gracias a la unidad de acción y criterio del gobierno nacional, que, sin embargo, se vieron progresivamente debilitados desde diciembre de 1921. Las renovadas fricciones entre junteros y africanistas, la postura ambigua del rey Alfonso XIII ante las mismas y la actitud cada vez más reticente de las fuerzas liberales de la coalición forzaron finalmente la crisis del gobierno Maura en marzo de 1922, dejando en suspenso los planes militares en Marruecos ${ }^{46}$.

No eran éstas, sin embargo, las dificultades más serias, ni tampoco las más trascendentales para el éxito de lo que ya empezaba a verse como la guerra del Rif. A medida que las tropas españolas volvían a ocupar sus antiguas posiciones, comenzó a hacerse evidente ante los ojos de muchos estrategas militares y comentaristas políticos que el avance español jamás podría culminarse sino contaba con la colaboración decidida y sin reservas de Francia ${ }^{47}$. Y eran ciertamente muchas las circunstancias que

\footnotetext{
${ }^{45}$ Lyautey a Briand, 26 de julio de 1921, MAEDI-M, leg. 620.

${ }^{46}$ Sobre la crisis del gobierno Maura puede verse Gonzalo Terreros Ceballos, "Antonio Maura y la cuestión marroquí". (Tesis Doctoral, UCM, 2013), 271-289.

47 "El problema capital de nuestro protectorado", de acuerdo con Berenguer. (Berenguer a Cierva, 13 de octubre de 1921, Fundación Archivo Antonio Maura, (FAMM), leg. 442/5).
} 
habían revelado, a alturas de diciembre de 1921, que el entendimiento con Francia sería una condición indispensable para coronar las campañas del Rif.

En primer lugar, las harcas del Rif habían continuado sus recorridos y desplazamientos hacia la zona francesa, de donde obtenían víveres y recursos y donde podían intercambiar los cartuchos y municiones obtenidos en su victoria contra los españoles, comercio a pequeña escala que era habitual en la región. Dichas comunicaciones habían sido parte tradicional del estilo de vida itinerante que dominaba en el territorio desde mucho antes de la instauración del Protectorado. La penetración española en el Rif, sin embargo, puso de manifiesto que su frecuencia y densidad dificultarían enormemente la progresión del Ejército de África, ya que ofrecían a las harcas una fácil opción de retirada y avituallamiento, desde la que podían reincorporarse a la resistencia contra las tropas españolas desde cualquier otro punto y en circunstancias más favorables.

La actitud de las tropas francesas en la región, por otra parte, no había alterado la que durante años había sido la disposición habitual de las autoridades vecinas hacia las tribus del Rif: una postura de inhibición y reserva encaminada a no interferir con las prácticas, usos y costumbres de la población local. En tanto que las cabilas rifeñas se limitaran a participar con su pequeño comercio en las zonas locales y no crearan dificultades o intentaran soliviantar a las tribus de la zona francesa, sus visitas podían llevarse a cabo sin impedimentos. El mariscal Lyautey había insistido particularmente en el mantenimiento de estas condiciones después de la derrota española de Annual ${ }^{48}$. A pesar del posible aprecio que pudiera tener por Berenguer, Lyautey no estaba dispuesto a modificar sus planes para el avance sobre la región de Taza, que ya se encontraba en un estado avanzado, ni a arriesgar una posible enemistad rifeña. De hecho, Lyautey consideraba que los españoles merecían hasta cierto punto lo ocurrido en el Rif, donde estaban pagando el precio por su actitud pro-alemana durante la Primera Guerra Mundial $^{49}$. Por otra parte, el mariscal francés mantenía que la rebelión rifeña era un movimiento exclusivamente anti-español, enraizado en una hostilidad histórica que se remontaba a los tiempos del Al-Ándalus y que se había revitalizado por la

\footnotetext{
${ }^{48}$ Lyautey a Briand, 2 de agosto de 1921, Service Historique de l'Armée de Terre, Vincennes, (SHAT), $3 \mathrm{H} / 132$.

${ }^{49}$ Lyautey a Briand, 27 de julio de 1921, MAEDI-M, leg. 620.
} 
incompetencia colonial de España y el odio creciente de los marroquíes. España estaba cosechando en Marruecos los frutos de su propia incapacidad como poder colonial y los resultados de su orgullosa actitud hacia Francia. Para Lyautey, el desastre de Annual no era sino la consecuencia inevitable de estas carencias, que no tenían por qué afectar a las cordiales relaciones entre las tribus rifeñas y las autoridades francesas ${ }^{50}$.

Esta reacción inicial dio lugar a situaciones paradójicas. Enviados de Abd el Krim, por ejemplo, entraron en contacto con los puestos avanzados franceses y llegaron a entrevistarse con algunos de sus mandos, a los que aseguraron sus intenciones pacíficas y el carácter específicamente anti-español de su resistencia ${ }^{51}$. Sus harcas pudieron intercambiar libremente material y municiones obtenidos del ejército español en los zocos y mercados del Protectorado francés y adquirir abundantes previsiones y víveres para el invierno. Las desventajas cada vez más evidentes que provocaba esta situación, de la cual las autoridades españolas se percataron abiertamente, dieron lugar a abundantes recriminaciones a las autoridades vecinas sobre estas prácticas ${ }^{52}$.

Los posibles acuerdos a los que pudieran haber llegado las conversaciones entre Berenguer y Lyautey sobre este asunto se vieron, sin embargo, eclipsados por el reemplazo de aquél y la llegada de un nuevo Alto Comisario a la zona española: el general Burguete, quinto representante de España en Marruecos y primer cambio en la alta jefatura de Tetuán tras los sucesos de Annual. El nombramiento de Burguete había sido resultado de la dimisión del gobierno Maura en marzo de 1922 — a la que se asoció Berenguer - y de la formación de un nuevo gobierno presidido por el conservador Sánchez Guerra. Otras razones, como el paulatino desaliento de la opinión pública ante el alargamiento de las campañas militares, habían contribuido a este relevo.

\section{El gobierno conservador de Sánchez Guerra (marzo-diciembre de 1922)}

Quizás la consecuencia más importante del cambio de gobierno fue el descarte de los planes de Berenguer para la finalización definitiva de las campañas del Rif y el

\footnotetext{
50 "Nuestra mejor baza" — concluía Lyautey — "es que los marroquíes no nos relacionen en nada con los españoles", Lyautey a Briand, 2 de agosto de 1921, SHAT 3H/132.

${ }^{51}$ Germain Ayache, "Les relations franco-espagnoles pendant la guerre du Rif", Españoles y franceses, op. cit., 287-293.

${ }^{52}$ Berenguer a Manuel González Hontoria, Ministro de Estado, 3 de septiembre de 1921, FAMM, 230/1.
} 
detenimiento de la ofensiva del Ejercito de África en la zona oriental. El empuje final en el Rif, esperado para el comienzo de la primavera, no tuvo lugar, y la resolución del problema marroquí, ocho meses después del desastre, se dejó en manos de negociaciones con los jefes rebeldes, a las que se dio prioridad sobre los avances militares.

Tal cambio de coordenadas no pareció sorprender excesivamente al mariscal Lyautey, acostumbrado quizá por entonces a los continuos vaivenes de la política colonial española. Las declaraciones un tanto altisonantes de Burguete, que abogaba por un entendimiento más estrecho con Francia y por una transformación en las relaciones con la población local, no tuvieron mucho efecto en él, que desde el principio receló del deseo de notoriedad del nuevo jefe militar y de la escasa correspondencia de sus proclamas con la realidad marroquí ${ }^{53}$. La situación del Ejército español en la zona oriental, lejos de mejorar, pareció deteriorarse, dando la razón a las previsiones de Lyautey. El plan de reconquista de Berenguer había establecido que el detenimiento del avance español sin haber conseguido objetivos fundamentales en el Rif no sería sino el comienzo de un retroceso gradual, y dichas circunstancias tuvieron visos de confirmarse a los pocos meses de la constitución del nuevo gobierno. Aliviadas por el término de las operaciones militares y espoleadas por las nuevas facilidades ofrecidas en la región, las harcas del Rif se limitaron a aprovechar las ventajas de la situación, en la que Abd el Krim se mostró como un experimentado interlocutor que supo explotar sin dificultad la debilidad de la posición española ${ }^{54}$.

No solo la situación del Rif, sino también las condiciones militares de la zona occidental parecieron resentirse de la nueva orientación adoptada por el Alto Comisario. Huido en las montañas desde comienzos del verano de 1922 y cada vez más arrinconado por los avances españoles, el Raisuni encontró en la suspensión de operaciones militares una oportunidad para mejorar su precaria posición y para ofrecer negociaciones que evitaran su definitivo sometimiento. Sus proposiciones a las autoridades españolas se

\footnotetext{
${ }^{53}$ Lyautey a Raymond Poincaré, Ministro de Asuntos Exteriores, 26 de septiembre de 1922, MAEDI-M, leg. 592. De acuerdo con el delegado de negocios extranjeros de la embajada francesa en España, Burguete "hablaba mucho". (Vienne a Poincaré, 2 de septiembre de 1922, MAEDI-M, leg. 622). Burguete sustituyó definitivamente a Berenguer en julio de 1922.

${ }^{54}$ Tah Tah, Entre reformisme..., op. cit., 61-86.
} 
hicieron, de ese modo, más frecuentes, así como su insistencia para formalizar un pacto que garantizara la estabilidad del territorio ${ }^{55}$.

En sus aspectos positivos, las nuevas prioridades del Ejército de África redujeron los encuentros militares y el número de bajas entre los soldados españoles, sobre todo en la región oriental. La reducción de fuerzas militares y el repatriamiento de las tropas llegadas a Marruecos en julio y agosto de 1921 también respondieron a los anhelos legítimos de la opinión pública en España, además de a las necesidades del presupuesto. Tales disposiciones, sin embargo, no parecían ofrecer una solución duradera ni una dirección clara al futuro de la presencia española en el Rif. Por el contrario, lo que comenzó a hacerse cada vez más evidente para los observadores nacionales y extranjeros era que las tropas españolas, limitadas en efectivos y reorganizadas en sus posiciones, no podían avanzar en el Rif, pero tampoco retroceder ${ }^{56}$. Las aspiraciones de un protectorado civil promovidas por las autoridades españolas con el fin de transformar las bases de la relación entre la administración colonial y la población local de algunas cabilas no dieron el resultado deseado. Ello no se debió tan solo a la escasa valía y consideración de que gozaban los representantes españoles entre las cabilas, sino también posiblemente al resentimiento y odio profundo que había provocado la brutalidad de la gestión colonial en los años precedentes, y que las autoridades españolas no supieron valorar en su justa medida ${ }^{57}$.

Parte esencial del escaso éxito de estas iniciativas se debía también a las oportunidades y alternativas que ofrecía a las cabilas del Rif el acceso irrestricto e ininterrumpido a la zona francesa, que garantizaba su reavituallamiento ante cualquier dificultad y restaba cualquier urgencia en el trato con los españoles. La importancia de la colaboración con Francia, que tan vital había parecido en opinión de Berenguer al inicio de las campañas del Rif, volvía a demostrarse ahora en circunstancias menos bélicas, pero igualmente decisivas para el general Burguete. En realidad, su estrategia acomodaticia con respecto a la población local descansaba enteramente sobre la premisa de que las tribus hostiles se dieran cuenta de que podían obtener más ventajas de las

\footnotetext{
${ }^{55}$ Tessainer, El Raisuni, op. cit., 211-233.

${ }^{56}$ Gral. Castro Girona, jefe del Gabinete Militar del Alto Comisario, a Niceto Alcalá-Zamora, ministro de Guerra, 15 de diciembre de 1922, AGMM-M, rollo 115, leg. 45.

${ }^{57}$ Pennel, A Critical..., op. cit., 484.
} 
negociaciones con las autoridades españolas que del acoso y violencia de las campañas militares. Dicho presupuesto nunca se cumplió, no solo por la memoria de los grandes botines conseguidos durante el desastre de Annual, sino particularmente porque la zona francesa ofrecía un refugio inexpugnable para las harcas rifeñas, que aprovecharon las nuevas ventajas de la situación sin renunciar al hostigamiento continuo de las posiciones españolas $^{58}$.

La actitud de Lyautey con respecto a la neutralidad francesa en el conflicto rifeño se mantuvo, por tanto, inalterable, y los intentos del general Burguete de mejorar las relaciones franco-españolas fueron tenues e infructuosos. El mariscal francés no dio jamás crédito a la premisa de que un esfuerzo negociador y pacificador pudiera alterar significativamente la situación de la zona española, y sus instrucciones a los puestos avanzados en las inmediaciones del Rif reiteraron los principios adoptados desde el desastre de Annual: inhibición general, libertad de circulación y acceso a los zocos y mercados de la zona francesa y discretos contactos con los jefes rebeldes si se presentaba la oportunidad ${ }^{59}$.

Cada vez más prisionero de las circunstancias, el gobierno Sánchez Guerra afrontó a lo largo del verano de 1922 una oposición creciente, que culminó con la llegada del otoño y la reapertura de las sesiones parlamentarias. Para entonces, las cuentas que se acumulaban en el débito del gabinete eran numerosas: las tensiones entre el poder civil y el militar, reflejadas en la renovada actividad de las Comisiones Informativas; la polémica creada en torno al expediente Picasso, que el gobierno proponía llevar al Parlamento, y, finalmente, la necesidad cada vez más imperiosa de una nivelación presupuestaria ${ }^{60}$. Sin embargo, como siempre en aquellos años, el problema marroquí constituía la razón principal de las cada vez más vociferantes discusiones parlamentarias. Las promesas de una rápida pacificación del territorio se habían demostrado vacías y la situación de las tropas españolas no había variado significativamente desde diciembre de 1921. Mientras que en la región occidental las relaciones con el Raisuni continuaban siendo tensas y dependientes de las prioridades

\footnotetext{
${ }^{58}$ Pennell, ibid., 467.

${ }^{59}$ Lyautey a Poincaré, 3 de julio de 1922, MAEDI-M, leg. 477. Lyautey dejó abierta la posibilidad de una futura rectificación de fronteras en el Rif.

${ }^{60}$ Véase Miguel Martorell Linares, José Sánchez Guerra: Un hombre de honor (1859-1935), (Madrid: Marcial Pons, 2011), 257-350.
} 
del jerife —a pesar de la firma de un acuerdo inicial en septiembre de 1922—, la situación en el Rif parecía languidecer en medio de iniciativas tímidas y huérfanas de dirección, que alternaban represalias militares con promesas de pacificación. En realidad, la disminución de efectivos y la repatriación de unidades no habían dado lugar a un abandono considerable de posiciones ni, por supuesto, a avances significativos. Tampoco habían permitido al gobierno una reducción verdaderamente sustancial de tropas en el territorio, que continuaban estancadas en unas condiciones en las que no se vislumbraban avances y en las que continuaban temiéndose las consecuencias de cualquier retroceso. La actitud de las tribus rifeñas continuaba siendo temible y su posible repercusión sobre otras cabilas del territorio preocupaba seriamente a los jefes militares españoles. Sabedoras de su dominio de la situación y conscientes de su renovado potencial militar en armamento, municiones y víveres provenientes de la zona francesa, las harcas del Rif apenas se vieron afectadas por la política de atracción pacífica del general Burguete, que hizo escasa huella en su disposición. Por el contrario, la figura de Abd el Krim ganaba en respeto y prestigio en la misma medida en que las autoridades españolas los perdían. En definitiva, el problema de Marruecos se estaba enquistando, y las opciones de los gobiernos peninsulares para remediarlo se estaban reduciendo peligrosamente ${ }^{61}$. La llegada de un nuevo invierno suspendió, una vez más, el futuro de la acción española en Marruecos, progresivamente inmerso en una huida hacia adelante.

\section{EI gobierno liberal de García Prieto (diciembre de 1922-septiembre de 1923)}

De manera quizás escasamente sorprendente, una de las tumultuosas sesiones parlamentarias de finales de otoño de 1922 finalizó con la dimisión del gobierno Sánchez Guerra, en medio de escenas que revelaban el faccionalismo y la desintegración gradual de las fuerzas políticas del régimen. Una vez más, un nuevo gobierno, esta vez en manos del liberal García Prieto, afrontó desde el mes de diciembre la tarea de resolver el problema marroquí, para lo cual nombró a un nuevo Alto Comisario, figura cada vez más alarmantemente asociada a los cambios de gobierno peninsulares. El nuevo Alto Comisario, Luis Silvela, por primera vez un civil, mantuvo

\footnotetext{
${ }^{61}$ Defrance, Embajador francés en España, a Poincaré, 8 de diciembre de 1922, SHAT, 3H/133.
} 
la suspensión de operaciones en la zona oriental, pero sobre todo favoreció una mejora real de las relaciones con Francia. Convencido de la necesidad de establecer contactos frecuentes y vínculos estrechos con las autoridades francesas $-\mathrm{y}$ en sintonía con el ministro de Estado, Santiago Alba, a quien se había otorgado la dirección de la política colonial_- Silvela realizó frecuentes gestiones y propuestas para entrevistarse con representantes franceses y coordinar y consensuar las iniciativas coloniales en ambos territorios. Lyautey, sin embargo, recibió con relativa frialdad tales aperturas. Para entonces, el mariscal francés (como muchos otros mandos de su ejército) estaba ya convencido de la crónica incapacidad colonial de España y de la irremediable inconsistencia de su política marroquí, que parecía rectificarse con la llegada de cada nuevo gobierno ${ }^{62}$. Cortés y distante en sus respuestas, su criterio sobre la actitud de los mandos franceses en el Rif no se vio alterado, y las ventajas que de ello se derivaban para las tribus rifeñas permanecieron intactas.

Fuera por los escasos avances concretos en las relaciones con Francia, por las crecientes presiones para aliviar la pesada carga del presupuesto o por el hastío creciente de la opinión pública, el caso es que la actuación del nuevo gabinete se orientó en un sentido más radical que el del gobierno anterior y se materializó en la instauración plena de la autoridad civil en el Protectorado y en el paralelo reemplazo de la autoridad militar. Tal proyecto, iniciado bajo los auspicios prometedores del rescate de los prisioneros cautivos tras el desastre de Annual —realizado en enero de 1923 y por el que Abd el Krim obtuvo cuatro millones de pesetas - , presentaba, sin embargo, algunas complicaciones que no tardaron en manifestarse.

En primer lugar, eran muy escasas las regiones de la zona española que se consideraban preparadas para la implantación de un protectorado civil, ya fuera por su estado de agitación o por la presencia cercana de harcas hostiles. Incluso las propias autoridades civiles reconocían esta dificultad, a la que añadían el problema de encontrar personal capacitado para realizar las tareas derivadas de la nueva estructura

\footnotetext{
${ }^{62}$ Lyautey a Poincaré, enero de 1923, MAEDI-M, leg. 478. Entre los tradicionales agravios franceses contra las autoridades españolas se encontraban las relaciones con Muley Hafid, antiguo Sultán enemigo de Francia, y los apoyos prestados a Abd el Malek en el Rif. Por parte española, se denunciaba particularmente la pasividad francesa ante las actividades rifeñas (que permitió, por ejemplo, la visita de una delegación rifeña a París en diciembre de 1922).
} 
administrativa del territorio ${ }^{63}$. El renovado prestigio de Abd el Krim en la región oriental —quien ya se presentaba en posición de igualdad con los españoles tras el rescate de los prisioneros - y del Raisuni en la zona occidental — que añadió nuevas demandas al pacto firmado en septiembre de 1922 - debilitaban también el pretendido alcance de la influencia civilista en el Protectorado. A pesar de que el nuevo Ministro de Estado, Santiago Alba, consideraba el entendimiento con Francia como una condición “esencial" para la solución del problema marroquí ${ }^{64}$, las nuevas medidas de su gobierno no hicieron paradójicamente sino provocar un renovado alejamiento en las autoridades vecinas. Para muchos observadores franceses, dichos proyectos no suponían, en realidad, sino el implícito reconocimiento de que España renunciaba verdaderamente a ejercer sus derechos en Marruecos ${ }^{65}$. El mariscal Lyautey, por su parte, concluyó que de la debilidad española se derivarían nuevas responsabilidades para Francia ${ }^{66}$.

Quizá la demostración más evidente de que no se consideraban suficientemente pacificadas las Comandancias Generales de Ceuta y Melilla era que el número de contingentes militares presentes en ambos territorios seguía sin disminuir significativamente, a pesar de la supresión de algunas posiciones. Mientras el Raisuni mantenía la región occidental en un estado de inquietud y alarma, Abd el Krim sostenía en sus negociaciones con los españoles su negativa a cualquier manifestación expresa de sumisión $^{67}$. Por el contrario, con la llegada del verano de 1923, la presión de las harcas del jefe rifeño sobre los puestos españoles volvió a hacerse más intensa, hasta el punto de hacer temer un nuevo descalabro militar con similitudes alarmantes con los sucesos de Annual. El fantasma de una nueva catástrofe en Marruecos volvió así a sobrevolar los informes cada vez más inquietantes recibidos por el gobierno de García Prieto, cuya política marroquí había descansado, incluso en mayor medida que durante el gobierno anterior, en la gestión política y civilista. Su ministro de Estado, Santiago Alba, quizás la figura más destacada del gabinete, comenzó a considerar la posibilidad de enviar

\footnotetext{
${ }^{63}$ Silvela a Alba, 28 de febrero de 1923, Archivo General de la Administración, (AGA), M24, 81/3.

${ }^{64}$ Alba a Quiñones de León, Embajador español en Francia, 17 de junio de 1923, AGA, M16, 81/3.

${ }^{65}$ Cuverville a Poincaré, 29 de diciembre de 1922, SHAT, 3H134.

${ }^{66}$ Lyautey a Poincaré, 23 de febrero de 1923, MAEDI-M, leg. 478. Sobre esas bases, y por miedo a provocar incidentes entre las tribus rifeñas, Lyautey desestimaría posteriormente la petición de las autoridades militares españolas de presenciar las operaciones francesas en Taza. Lyautey a Poincaré, 12 de mayo de 1923, MAEDI-M, leg. 478.
}

${ }^{67}$ Pennell, A Critical..., op. cit., 618-619. 
refuerzos desde la Península para hacer frente a la nueva ofensiva rifeña y, más privadamente, el empleo de gases asfixiantes para defender las posiciones españolas ${ }^{68}$.

En definitiva, en julio de 1923, las autoridades españolas en Marruecos no habían conseguido aún consolidar el control y el dominio del territorio, sobre todo en la zona oriental. Mientras el Raisuni continuaba manteniendo en vilo a la Comandancia de Ceuta, la línea avanzada de posiciones en Melilla seguía expuesta a los ataques de las harcas y en una situación de vulnerabilidad aparentemente similar a la que había demostrado dos años antes. Nuevas operaciones militares en el Rif (descartadas prácticamente desde diciembre de 1921) volvieron a tener en lugar en verano de 1923, poniendo de manifiesto el enquistamiento crónico que parecía estar adquiriendo el problema marroquí.

Junto con otros motivos bien conocidos, como la violencia desatada en las calles de Barcelona desde comienzos de 1923, la pérdida de prestigio de los partidos dinásticos $\mathrm{y}$, posiblemente, la cercana presentación en las Cortes de las conclusiones del Expediente Picasso elaboradas por el Consejo Supremo de Guerra y Marina, el pronunciamiento de Primo de Rivera tuvo como desencadenante principal la situación de Marruecos, causa final y distintiva del derrumbamiento del régimen liberal en España $^{69}$.

\section{UN RETO IMPOSIBLE PARA LA DICTADURA (1923-1926)}

Primo de Rivera era un abandonista convencido, algo que no era un secreto, y su actitud inicial en el embrollo marroquí (ese "cien veces maldito asunto" ${ }^{70}$ ) era relativamente clara, aunque posiblemente simplista: el abandono de la zona española y su intercambio por otros territorios de mayor trascendencia para los intereses nacionales. La imposibilidad de estas propuestas acabó decidiendo su posterior estrategia de

\footnotetext{
${ }^{68}$ Esta última estrategia se incluía en las propuestas militares recibidas por el ministro de Estado en julio de 1923. ARAH, Fondo Santiago Alba, 4/50-5.

${ }^{69}$ Véase Francisco J. Romero y Angel Smith, "La Agonía del liberalismo español y los orígenes de la dictadura en el contexto europeo", en Francisco J. Romero y Angel Smith (eds.), La Agonía..., op. cit., (Granada: Comares, 2014), pp. 1-30.

${ }^{70}$ Primo de Rivera a gral. Sanjurjo, Cte. Gral. de Melilla, 20 de agosto de 1924, AGMM-M, r. 573, leg. $409 / 9$.
} 
repliegue hacia las posiciones costeras y la evacuación del interior de la zona española, una retirada que creó problemas innumerables para Francia y que acabaría condenando a ambos países a entenderse en Marruecos.

\section{Un intercambio impracticable}

Las primeras iniciativas que el Presidente del Directorio militar adoptó en este sentido - una propuesta de intercambio de Ceuta por Gibraltar — produjeron irritación en las cancillerías extranjeras, que prontamente hicieron saber su desaprobación de tales proyectos a los representantes diplomáticos españoles ${ }^{71}$. La ingenuidad del dictador se extendía también a las consideraciones estratégicas de la seguridad nacional, para él no tan evidentes, y a la actitud de buena parte del ejército y del rey Alfonso XIII, completamente opuestos a un abandono de Marruecos. Llevó, por tanto, un tiempo a Primo darse cuenta de que la salida del atolladero marroquí no era ni tan evidente ni tan practicable como había supuesto antes de llegar al poder. Sus infructuosas expectativas para desembarazar a España de la carga en que se había convertido Marruecos se vieron así reemplazadas por una actitud cada vez más realista, encaminada una vez más a intentar cambiar el rumbo de las relaciones con Francia al otro lado del Estrecho ${ }^{72}$.

La primera visita de Primo a Marruecos debió de convencerle probablemente de que ése tampoco era un camino sencillo. A las muestras escasamente disimuladas de menosprecio e insubordinación latente por parte de los mandos de muchas unidades coloniales españolas, que veían en Primo al liquidador de la empresa colonial, se unieron las mil filigranas diseñadas por Lyautey para evitar encontrarse con él. Primo se había ofrecido a visitar la zona francesa para saludarle oficialmente y ponerle al corriente de sus planes para el futuro de Marruecos, pero Lyautey buscó motivos y obligaciones "inexcusables" para mantenerse en la zona de vanguardia francesa ${ }^{73}$. El resultado fue la relativamente deshonrosa posición en que se vio el dictador, que tan solo pudo entrevistarse con algunos subordinados del Mariscal en una primera toma de

\footnotetext{
${ }^{71}$ Sir Ronald Campbell, Head of Western Department, FO, a Alfonso Merry del Val, embajador español en Londres, 31 de enero de 1924, NA FO 371/10577.

${ }^{72}$ Susana Sueiro Seoane, España en el Mediterráneo. Primo de Rivera y la “cuestión marroquí”, 19231930 (Madrid: UNED, 1992), pp. 188-362.

${ }^{73}$ Lyautey a Édouard Herriot, Primer ministro francés, 18 de julio de 1924, CADN, CD/243.
} 
contacto cortés, pero escasamente fructífera. Su experiencia en la zona francesa probablemente convenció a Primo de que era inútil esperar una postura receptiva de Francia en Marruecos y de que España debía actuar inmediatamente, con o sin el beneplácito francés. Su respuesta ante las circunstancias finalmente se concretó en una decisión trascendente: el abandono de los puestos avanzados españoles en las Comandancias de Ceuta y Melilla y su retirada a una línea de posiciones mucho más cercanas a los enclaves costeros.

El plan de retirada de Primo, que ya había sido sugerido en años anteriores por otros representantes políticos, contó con la esperada desaprobación de los mandos del Ejército de África y con la incredulidad de las autoridades francesas. En sí mismo, se trataba de un plan legítimo, un repliegue de posiciones para reducir gastos y para reordenar la administración del territorio, pero en muchos aspectos resultaba un retroceso que cambiaba enteramente la contextura de la situación en Marruecos. A Primo se le había advertido que un plan de dichas características provocaría un número elevado de bajas, probables pérdidas de material y armamento de las tropas evacuadas e incluso una posible repetición de los sucesos de Annual si los mandos militares se veían importantes para contener a sus soldados (y a sus oficiales) ante el asedio de las cabilas $^{74}$. Dichos vaticinios se cumplieron en su mayor parte en noviembre de 1924 y el abandono de posiciones españolas resultó una empresa enormemente costosa y arriesgada, que dejó miles de víctimas y en la que se perdieron abundantes armamento y $\operatorname{recursos}^{75}$.

Resulta arduo verificar si Primo era consciente de la difícil situación en que su retirada dejaría a las autoridades militares francesas. Verdaderamente, se daba poco menos que por descontado que Abd el Krim utilizaría el repliegue de las fuerzas españolas para afianzar su posición en el Rif y para extender su dominio en la región, aunque resultaba incierto el curso que tomarían los acontecimientos tras estos avances. Si Primo utilizó su retirada para provocar un contexto que obligara a Francia a

\footnotetext{
${ }^{74}$ Particularmente Sanjurjo, Cte. Gral. de Melilla, (Sanjurjo a Primo, 27 de Agosto de 1924, AGMM-M, rollo 573, leg. 404/9).

${ }^{75}$ Véase Shannon Fleming, Primo de Rivera and Abd el Krim, The Struggle in Spanish Morocco, 19231927. (Tesis, Universidad de Wisconsin, 1974), pp. 195-202.
} 
abandonar su indiferencia y a mostrarse más afín a España es una hipótesis interesante, aunque probablemente excesiva.

Para el mariscal Lyautey, en cualquier caso, las noticias del abandono español supusieron una contrariedad importante. El Residente General francés se quejó amargamente a su gobierno de que las autoridades españolas hubieran tomado esta iniciativa sin consultar con él y avanzó importantes consecuencias para sus planes de operaciones en Taza, que continuaban siendo su prioridad fundamental. Lyautey percibió claramente entonces que la evacuación de puestos españoles provocaría consecuencias en la zona francesa, sobre todo entre las tribus más próximas al Rif, y que sería necesario aminorar los avances militares para tener éstas en cuenta. El Residente General, sin embargo, se mostró más partidario que nunca de mantener una actitud estrictamente neutral ante la situación y de no interferir de ningún modo en la misma, con el fin de no ofrecer a Abd el Krim motivos ni pretextos para atacar la zona francesa. Lyautey continuaba convencido de que el conflicto del Rif era esencialmente un levantamiento anti-español, y se resistió a considerar la idea de que el caudillo rifeño estuviera acaudillando un movimiento de liberación anti-europeo o anti-colonial, no solo por la pésima opinión que tenía de la zona española, sino también por la imagen quizá un tanto distorsionada que conservaba de la colonización francesa ${ }^{76}$. A pesar de que los razonamientos de Lyautey parecieron convencer al gobierno Herriot (19241925), que apoyó sin reservas sus disposiciones, el giro que estaba tomando la situación en el Rif sugería que las previsiones del mariscal podían verse fácilmente superadas.

Abd el Krim, como era de esperar, se sirvió de la retirada española para mejorar los recursos y el equipamiento de sus harcas, para consolidar su liderazgo en el Rif y también para eliminar la competencia del Raisuni en el frente occidental, convirtiéndose así en el verdadero y único líder de la resistencia contra los españoles. Desde algún tiempo antes, el caudillo rifeño se había preocupado también de imprimir un carácter particular y distintivo a su lucha contra los españoles, que él quería diferenciar de la rebeldía tradicional y volátil de las cabilas rifeñas. Probablemente inspirado por su experiencia y contacto con la administración española, y sin duda favorecido por su inteligencia, astucia y dotes de mando, Abd el Krim trató de dar a su resistencia una

\footnotetext{
${ }^{76}$ Lyautey a Herriot, 14 y 15 de noviembre de 1924, CADN, CD243.
} 
continuidad y organización desconocida hasta entonces en el Rif, para lo cual utilizó una variedad de recursos, entre los que se incluían nuevas vías de comunicación y transporte, establecimiento de bases y puestos permanentes, cadenas de autoridad y mando, y división de responsabilidades. Parte importante de dicha naciente estructura de mando y gobierno en el Rif, que tanta irrisión producía entre los mandos españoles, eran las relaciones con las diversas potencias europeas que albergaban intereses encontrados en Marruecos, cuya importancia Abd el Krim pareció comprender en seguida. Bien instruido por sus actividades durante la Gran Guerra sobre las tensiones internacionales que confluían en el Sultanato, Abd el Krim intentó dotar a su República del Rif de una entidad, apariencia y solidez que le permitieran proyectarla en el escenario estratégico del Mediterráneo Occidental. Dichas ambiciones, que ya habían comenzado a esbozarse en años anteriores, adquirieron a partir de la retirada española una apariencia más definida, y el número de iniciativas, proclamas, declaraciones y ofrecimientos a las naciones europeas - en muchos casos a través de agentes y colaboradores europeos que residían en Tánger-, se hizo más frecuente y visible ${ }^{77}$. Inevitablemente, la propagación de una imagen internacional de la República del Rif resultaba problemática por muchos motivos, entre otros por las contradicciones que en sí misma reflejaba. Abd el Krim podía ofrecerse, por ejemplo, como un líder religioso que acaudillaba la resistencia del Islam contra los invasores cristianos - un perfil que le valió la admiración y el apoyo de los movimientos pan-islámicos de entreguerras-, al mismo tiempo que ofrecía las riquezas del Rif a los consorcios mineros alemanes y franceses que pudieran estar interesados. El jefe rifeño podía asimismo presentar su República del Rif como el origen de un movimiento democrático en la región, al mismo tiempo que sus harcas actuaban como fuerzas de ocupación en la mayoría de las cabilas del territorio. En realidad, es posible que el mismo Abd el Krim favoreciera dichas contradicciones e inconsistencias, que le permitían ofrecerse como respuesta para todos los que guardaban esperanzas o intereses en el Rif y, sobre todo, contribuían a hacer más compleja y densa una red de malentendidos y rumores en la que él se mantenía como centro ${ }^{78}$.

\footnotetext{
${ }^{77}$ Madariaga, Abd el Krim...op. cit., pp. 444-469.

${ }^{78}$ Una interesante presentación de dichos motivos en Nathaniel Berman, “'The Appeals of the Orient': Colonized Desire and the War of the Riff'. En Karen Knop. (ed.), Gender and Human Rights (Oxford: OUP, 2004), 195-230.
} 
Cualquiera que fuera la coherencia interna de su propaganda, Abd el Krim tuvo éxito en atraer las miradas de la prensa europea y de diversas instituciones internacionales y, sobre todo, en asegurar su visibilidad como líder de un movimiento de resistencia ante el colonialismo europeo, una imagen que viajó desde Latinoamérica hasta el Extremo Oriente ${ }^{79}$. Fue precisamente esta notoriedad del jefe rifeño y las posibles repercusiones internacionales de la guerra del Rif las que determinaron, en mayor medida que otros acontecimientos, su desenlace final.

A medida que se engrandecía la imagen del jefe rifeño y el eco de la guerra del Rif, se hacían más evidentes las posibles complicaciones para las potencias más directamente interesadas en Marruecos y, sobre todo, la posibilidad de una mediación internacional como solución al conflicto. La situación se hizo aún más grave cuando, en abril de 1925, las harcas rifeñas atacaron finalmente la zona francesa y demolieron la línea defensiva establecida para contener sus posibles avances. Lyautey había previsto, ciertamente, que para la llegada de la primavera y ante la magnitud del abandono español, Abd el Krim se vería probablemente inclinado a dirigir sus esfuerzos contra los franceses. El Residente General, sin embargo, se había cuidado de señalar a su gobierno que tal contingencia era resultado directo del repliegue español, con el fin posiblemente de salvar sus anteriores estimaciones sobre el carácter exclusivamente anti-español del movimiento del Rif. De cualquier modo, Lyautey había previsto ante dicha eventualidad un reforzamiento de los puestos franceses que finalmente se reveló insuficiente - Abd el Krim llegó a penetrar profundamente en el Protectorado francés y estuvo cerca de tomar Fez- y que obligó a replantear enteramente la estrategia militar de la zona francesa ${ }^{80}$.

La deriva de las circunstancias comenzó a inquietar, en especial, al Foreign Office británico, a quien preocupaba la prolongación que se suponía que iba a adquirir el conflicto y la creciente atención y críticas que estaba provocando en foros internacionales, como la Sociedad de Naciones o el Comité Internacional de la Cruz

\footnotetext{
${ }^{79}$ Véase Tayeb Boutbouqalt, La Guerre du Rif et la réaction de l'opinion internationale, 1921-1926, (Casablanca: Najah El Jadida, 1992), 36 y ss.

${ }^{80}$ Sobre los errores de apreciación de Lyautey véase Rivet, Lyautey, op. cit., 156-157 y Gershovich, French Military..., op. cit., 127-131
} 
Roja $^{81}$. Las prioridades británicas pasaban, por el contrario, por una resolución pronta de las campañas militares que permitiera reestablecer la situación y restaurar el equilibrio de fuerzas en el Mediterráneo Occidental. La presión diplomática ejercida sobre el Quai d'Orsay para evitar a toda costa la internacionalización del conflicto no se hizo esperar, al igual que las urgentes conminaciones para poner punto final al “embrollo" del Rif ${ }^{82}$.

Dicha confluencia de circunstancias, que habían llegado a prever algunos mandos españoles, resultó fatal para Lyautey, que continuaba ofreciendo a su gobierno planes de actuación basados en la reconstrucción paciente de contactos políticos con las cabilas afectadas y en limitados movimientos militares de contención y avance, que continuaban descartando cualquier cooperación con las autoridades vecinas. Independientemente de que dicha estrategia pudiera tener éxito a largo plazo, lo que resultaba evidente es que no iba a ser capaz de poner punto final al problema del Rif en un plazo breve, algo cada vez más prioritario para el gobierno de Paul Painlevé y su coalición de partidos de izquierda ${ }^{83}$.

Fue finalmente la urgencia de poner fin a la guerra del Rif — algo que Lyautey no pareció apreciar en toda su gravedad-y el hecho de que la cooperación con España se viera como absolutamente necesaria para dicho fin, lo que decidió finalmente la suerte del mariscal francés. De manera cauta y progresiva, el gobierno de Painlevé comenzó a asentar su prioridad de establecer un acuerdo político con España (completado en julio de 1925) y su aprecio por interpretaciones alternativas sobre la estrategia militar a seguir en Marruecos, contexto en el que la figura de Pétain adquirió cada vez mayor relevancia, a medida que la de Lyautey se empequeñecía ${ }^{84}$. La llegada de Pétain a Marruecos supuso un revulsivo para la iniciativa francesa, que se concretó en inmediatas visitas a la zona española e intercambios de información con sus

\footnotetext{
${ }^{81}$ Una visión interesante en Anna Chotzen "Beyond Bounds: Morocco's Rif War and the Limits of International Law", Humanity, 5/1 (2014): 33-54.

82 "Por el amor del cielo", pidió Austin Chamberlain al embajador francés en Londres, "que Francia no convierta un conflicto interno en una cuestión internacional" (Chamberlain a Fleuriau, 22 de diciembre de 1924, NA FO 371/10584).

${ }^{83}$ Hervé De Charette, Lyautey, (París: Lattes, 1997), 203 y 267. Painlevé reemplazó a Herriot como primer ministro en abril de 1925.

${ }^{84}$ Sobre las relaciones entre Lyautey y Pétain, véase Max Schiavon, La guerre du Rif : Un conflit colonial oublié - Maroc (1925-1926), (París: Pierre de Taillac, 2016), pp. 71-158.
} 
autoridades y en la elaboración de un plan militar conjunto que ya estaba finalizado para agosto de 1925. Pétain fue nombrado Comandante en Jefe de las operaciones, mientras que Lyautey retuvo la Residencia General en una nueva división de las responsabilidades operada en el Protectorado francés. Razones apropiadas y convincentes comenzaron a sugerirse entonces para facilitar una transición completa de mando que fuera pacífica y discreta, y cuyo desenlace tuvo lugar en septiembre de 1925. Lyautey regresó a Francia en octubre y Pétain permaneció en Marruecos como Comandante en Jefe de las fuerzas coloniales francesas.

La estrategia militar de Pétain, muy diferente de la de Lyautey, se concentró en operaciones decisivas, a escala casi continental, y para las que el héroe de Verdún contó con material y armamento abundantes y tropas de refresco enviadas desde la metrópoli. Más allá de lo adecuada o foránea que pudiera resultar su estrategia en el entorno colonial, lo cierto es que el nuevo Comandante en Jefe respondía con su disposición a las aspiraciones del gobierno francés de acabar cuanto antes con el problema marroquí. Parte fundamental de dichos planes, como se dijo, fue la actitud radicalmente distinta que adoptó Pétain con respecto a la colaboración con España en Marruecos. Los primeros contactos entre Pétain y Primo ya habían puesto de manifiesto una inmediata cordialidad y una sintonía muy diferente de la correcta frialdad de años anteriores, que facilitaron el intercambio de planes militares y la cooperación para el éxito de los mismos ${ }^{85}$.

La celeridad y el dinamismo con que se pusieron en marcha nuevas operaciones de avance (que en la zona española habían cesado prácticamente desde 1921) tuvo probablemente como acicate la llegada del invierno marroquí y la inevitable paralización de movimientos que se produciría entonces. El desembarco de Alhucemas, piedra de toque de esta nueva colaboración franco-española, plasmó esta cooperación particularmente en dos extremos: el avance y el hostigamiento de las tropas francesas en el sur, por la retaguardia de las posiciones rifeñas, y la llegada de destacamentos de soldados españoles por el norte, desde la zona delimitada por el repliegue del año anterior. Ello obligó a Abd el Krim, por primera vez desde el comienzo de su epopeya, a dividir sus fuerzas en dos frentes simultáneos.

\footnotetext{
${ }^{85}$ Sueiro, Primo de Rivera, op. cit., pp. 250-313.
} 
La estabilidad del proyecto resultó garantizada por la entereza francesa y la acometividad española, no exenta de fortuna, que hizo posible finalmente el fondeamiento de barcos de guerra en Alhucemas ${ }^{86}$. El desembarco de tropas y el continuo refuerzo de las mismas desde septiembre de 1925 permitió que la llegada del invierno encontrara al avance español, por primera vez desde el desastre de Annual, en una posición de superioridad estratégica. Consciente de la necesidad de romper este movimiento envolvente, Abd el Krim intentó maniobras para debilitar la entente francoespañola y para crear fracturas y grietas que permitieran sobrevivir a su República del Rif. En esta ocasión, sin embargo, dichas tácticas no produjeron resultados. La reanudación de operaciones militares en la primavera de 1926 confirmó lo que ya muchos anticipaban desde el invierno anterior: la derrota de la resistencia en el Rif y el final de la guerra. En mayo de 1926, el caudillo rifeño se entregó a las autoridades francesas $^{87}$.

La derrota de Abd el Krim, que tan lejana había parecido en años anteriores, se había conseguido en apenas ocho meses, empleando medios y estrategias militares quizá poco habituales en el escenario colonial y, sobre todo, desafiando la que se había convertido en práctica habitual y aceptada desde el establecimiento del Protectorado marroquí: la rivalidad y la desconfianza mutua entre las potencias protectoras en Marruecos. Para la dictadura de Primo de Rivera, cuyos primeros pasos se habían visto claramente amenazados por el problema marroquí, el final de las campañas militares, en las que Primo había participado tan activamente, supuso un espaldarazo y un enorme respaldo a su continuidad. Lo que había comenzado siendo un problema crónico y aparentemente irresoluble, se convirtió así en la mayor prueba de la popularidad del dictador $^{88}$.

\footnotetext{
${ }^{86}$ Según el delegado militar de la Embajada británica, presente en las operaciones, el desembarco equivalió a una exhibición individual de Primo ("a one man show"), que asumió la jefatura absoluta de toda la operación. "Todo y todos dependían de él". (Comandante Torres a Chamberlain, 15 de octubre de 1925, NA FO 371/11080). Una visión menos fortuita en Sueiro, España en el Mediterráneo, op. cit., pp. 187-193, 250-313.

${ }^{87}$ Madariaga, Abd el Krim, op. cit., p. 469-490. La "pacificación" final de la zona española, sin embargo, no se completaría hasta el año 1927.

${ }^{88}$ Sueiro, "El mito del estratega. Primo de Rivera y la resolución del problema de Marruecos", Cuadernos de Historia Contemporánea, 16, (1994), pp. 113-130.
} 
Para el Protectorado francés, la derrota de Abd el Krim despejó nuevamente la ruta hacia la dominación definitiva del territorio, que se conseguiría ocho años después con la toma de Taza. La experiencia final de la guerra del Rif no solo permitió al gobierno Painlevé un breve respiro, sino que también elevó a Pétain a nuevas cotas de admiración y prestigio. Lyautey, sin embargo, observó con desdén e indiferencia afectada la conclusión de las operaciones, cuya magnitud y dimensiones siempre consideró ajenos a su paciente y metódica labor de años anteriores ${ }^{89}$.

\section{CONCLUSIONES}

El problema de Marruecos desencadenó la crisis final de la Restauración en España y se convirtió en el obstáculo más formidable que hubo de afrontar la dictadura de Primo de Rivera. En ambas circunstancias, la aparente irresolución crónica de la situación en Marruecos descansaba en un conjunto de factores que recorrían desde las escasas capacidades coloniales de España hasta la impopularidad de la aventura marroquí, pasando por las carencias y vicisitudes del ejército español.

Un denominador común a estos condicionantes, junto con los escasos recursos, la difícil geografía y el carácter indómito de las cabilas de la zona española, fue el escaso entendimiento y la rivalidad con las que se iniciaron las relaciones francoespañolas en Marruecos, que se acentuarían durante la Primera Guerra Mundial, hasta cristalizar en una actitud de sospecha, recelo y resentimiento alimentada por agravios comparativos, que hizo imposible una respuesta coherente ante la resistencia nativa, sobre todo en el Rif. El prolongamiento fatal de dichas circunstancias acabó con los últimos gobiernos liberales en España y abrumó a los primeros gabinetes de la Dictadura. Tan solo cuando se dieron las condiciones propicias para navegar el complejo laberinto internacional en que estaba sumida la colonización marroquí se abrió, finalmente, la posibilidad de un desenlace afortunado para España y Francia en los territorios del otro lado del Estrecho.

\footnotetext{
${ }^{89}$ Rivet, Lyautey..., op.cit., 302 y Gershovich, French Military, op. cit., 133.
} 


\section{BIBLIOGRAFÍA}

Allain, Jean-Claude. Agadir, 1911. París, Publications de la Sorbonne, 1976.

Allendesalazar, José Manuel. La diplomacia española y Marruecos, 1907-1909. Madrid: AECI, 1990.

Ayache, Germain, "Les relations franco-espagnoles pendant la guerre du Rif", en Españoles y franceses en la primera mitad del siglo XX, 287-293. Madrid: CSIC, 1986.

Balfour, Sebastian. The End of the Spanish Empire. Oxford: OUP, 1997.

--. Abrazo mortal: De la guerra colonial a la Guerra Civil en España y Marruecos (1909-1939). Barcelona: Península, 2002.

-- "La conformación de un ejército intervencionista, 1898-1923". En La agonía del liberalismo español. De la revolución a la dictadura, 1913-1923, Francisco J. Romero Salvadó y Angel Smith (eds.), 255-272. Granada: Comares, 2014.

Benjelloun, Abdelmajid. Approches du colonialisme espagnol et du mouvement nationaliste marocain dans l'ex-Maroc khalifien. Rabat: Okad, 1988.

Benjelloun, Thérèse. Visages de la diplomatie marocaine depuis 1844. Casablanca: Eddif, 1991.

Berman, Nathaniel, "The Appeals of the Orient': Colonized Desire and the War of the Riff'. En Gender and Human Rights, Karen Knop (ed.), 195-230. Oxford: OUP, 2004.

Boutbouqalt, Tayeb, La Guerre du Rif et la réaction de l'opinion internationale, 19211926. Casablanca: Najah El Jadida, 1992.

Boyd, Carolyn P. La política pretoriana en el reinado de Alfonso XIII. Madrid: Alianza, 1990.

Chandler, James A. "Spain and Her Moroccan Protectorate 1898-1927", Journal of Contemporary History, 10/2, (1975), 301-322.

Charette, Hervé de. Lyautey. París: Lattes, 1997.

Chotzen, Anna. "Beyond Bounds: Morocco's Rif War and the Limits of International Law", Humanity, 5/1 (2014): 33-54.

Delaunay, Jean-Marc, Méfiance cordiale. Les relations franco-espagnole de la fin du XIXe siècle à la Première Guerre mondiale, 3 vols. París: L'Harmattan, 2010.

Dipublico.org. $\quad$ https://www.dipublico.org/108651/convenio-fijando-la-respectivasituacion-de-espana-y-francia-en-marruecos-firmado-en-madrid-el-27-denoviembre-de-1912/. 
Fernández Riera, Vicente. De Cuba a Annual. Vida y muerte del General Silvestre (1871-1921). Madrid: Almena, 2018.

Gárate Bajo, María. "Las campañas de Marruecos y la opinión pública. Una puesta al día”, Hispania, 79/263, (2019), 727-756.

Gershovich, Moshe. French Military Rule in Morocco: Colonialism and Its Consequences. Londres: Frank Cass, 2000.

Goicoechea, Antonio, El problema de Tánger y la opinión española. Madrid: Voluntad, 1923.

Harris, Walter B. France, Spain and the Rif. Londres: Arnold, 1927.

Hernando de Larramendi, Miguel (coord.), Historia y memoria de las relaciones hispano-marroquíes. Madrid: Ediciones del Oriente y del Mediterráneo, 2007.

Hoisington Jr., William A. Lyautey and the French conquest of Morocco. Basingstoke: Palgrave Macmillan, 1995.

Hunter Miller, David, My diary at the Conference of Paris: with documents. 21 vols. (Nueva York: 1924).

Jover Zamora, José María. Política, Diplomacia y Humanismo popular. Madrid: Turner, 1976.

Julien, Charles-André. Le Maroc face aux impérialismes. 1415-1956, París, Jeune Afrique, 1978.

Kabbani, Rashid. Morocco: From Protectorate to Independence, 1912-56. Washington: The American University, 1957.

Kharchich, Mohamed. "Les négociations franco-rifaines 1924-1926: un processus lent et illusoire", Revue d'histoire maghrébine, 18/63-64, (1991), 295-313.

Koerner, Francis, "La guerre du Rif espagnol vue par la Direction des Affaires indigènes française (1921-1924)", Revue historique, 581/1, (1992), 141-156.

Kunz, Rudibert y Müller Rolf-Dieter, Giftgas gegen Abd el Krim: Deutschland, Spanien und der Gaskrieg in Spanisch-Marokko, 1922-1927. Freiburg-im-Breisgau, Verlag Rombach, 1990.

Madariaga, María Rosa de. Abd el-Krim el Jatabi. La lucha por la independencia. Madrid: Alianza Ensayo, 2009.

Martorell Linares, Miguel. José Sánchez Guerra: Un hombre de honor (1859-1935). Madrid: Marcial Pons, 2011.

Miller, Susan. A History of Modern Morocco. Cambridge: CUP, 2013.

Morales Lezcano, Víctor, España y el norte de África. El protectorado en Marruecos (1912-1956). Madrid: UNED, 1986. 
Payne, Stanley G. Politics and the Military in Modern Spain. Stanford: SUP, 1967.

Pennell, Charles R. "A critical investigation of the opposition of the Rifi confederation led by Muhammed bin'Abd al-Karim al-Khattabi to Spanish colonial expansion in northern Morocco, 1920-1925, and its political and social background", 2 vols. Tesis doctoral, Universidad de Leeds, 1979.

Pennell, Charles R. "How and why to remember the Rif War (1921-2021)", The Journal of North African Studies, 22:5, (2017), 798-820.

Pereira Castañares, Juan Carlos. "El contencioso de Tánger en las relaciones hispanofrancesas (1923-1924)", en Españoles y franceses en la primera mitad del siglo XX, 303-322. Madrid: CSIC, 1986.

Pérez Ortiz, Eduardo. De Annual a Monte Arruit. Melilla, 1923.

Perry, John. "A Shared Sea: The Axes of French and British Imperialism in the Mediterranean, 1798-1914". En British and French Colonialism in Africa, Asia and the Middle East, James R. Fichter (ed.), 113-130. Cham: Palgrave Macmillan, 2019.

Rivet, Daniel, Lyautey et l'institution du protectorat français au Maroc, 1912- 1925, 3 vols. París: L’Harmattan, 1988.

Rohl, John G. Wilhelm II: Into the Abyss of War and Exile, 1900-1941. Cambridge: CUP, 2017.

Ruíz Albéniz, Víctor España en el Rif . Melilla, Ayuntamiento de Melilla, 1994 (1 $1^{\mathrm{a}}$ ed. 1921).

Sasse, Dirk, Franzosen, Briten und Deutsche im Rifkrieg 1921-1926. Munich: Oldenbourg, 2006.

Schiavon, Max. La guerre du Rif : Un conflit colonial oublié - Maroc (1925-1926). París: Pierre de Taillac, 2016.

Serrat y Bonastre, Francisco de Asís, Tánger, 1916-1924. Granada: Alced, 2017.

Sueiro Seoane, Susana. España en el Mediterráneo. Primo de Rivera y la "Cuestión Marroqui", 1923-1930. Madrid: UNED, 1992.

--, "El mito del estratega. Primo de Rivera y la resolución del problema de Marruecos", Cuadernos de Historia Contemporánea, 16, (1994), pp. 113-130.

TahTah, Mohamed "Entre pragmatisme, réformisme et modernisme: le rôle politicoreligieux des Khattabi dans le Rif (Maroc) jusqu'à 1926", Tesis doctoral, Universidad de Leiden, 1995), pp.59-79.

Terreros Ceballos, Gonzalo. “Antonio Maura y la cuestión marroquí”. Tesis Doctoral, Universidad Complutense, 2013. 
Tessainer y Tomasich, Carlos-Federico. El Raisuni. Aliado y enemigo de España. Málaga: Algazara, 1998.

Wolf, Jean, Les secrets du Maroc espagnol. Casablanca, Eddif: 1994.

Woolman, David S., Rebels in the Rif: Abd el Krim and the Rif Rebellion. Stanford: SUP, 1968. 